\title{
Using modeling to select catalyst dilution methods for mass transfer intensification in lab gas-liquid fixed-bed reactors
}

\author{
Alberto Servia* \\ IFP Energies nouvelles, Rond-point de l'échangeur de Solaize, BP 3, 69360 Solaize, France
}

Received: 25 June 2020 / Accepted: 7 September 2020

\begin{abstract}
Heterogeneous catalyst testing methodology at the lab scale must provide intrinsic kinetics data for reactor design purposes as well as the intrinsic activity ranking during catalyst screening in the field of refining and petrochemistry. The significant downscaling of the past century coupled with the increasingly active catalytic formulations may introduce considerable momentum, mass and heat effects in experiments at small scale. Catalyst dilution has emerged as one versatile and robust way to reduce the impact of momentum and heat effects on heterogeneous catalyst testing. This paper presents a methodology based on global phenomena and catalyst dilution modeling to assess and optimize reactor loading techniques for specific problems. More particularly, the aim is to provide catalysts developers and kinetics experts with concrete guidelines for intensifying gas-liquid mass transfer in lab gas-liquid fixed-bed reactors through catalyst dilution. The methodology is applied to the kinetics determination of the oil residue Hydrodemetallation (HDM) and to the screening of catalysts for benzene hydrogenation. Layered dilution, consisting on the split of the catalyst in two beds separated by an intermediate bed containing an inert material of the same size as the catalyst, poorly improves gas-liquid mass transfer. Uniform dilution, based on the direct mixture of catalyst and inert material of the same size, significantly enhances gas-liquid mass transfer as the reactant local consumption per reactor unit volume is strongly reduced. Combinations of both abovementioned dilution techniques can be used with fast and/or high stoichiometric factor chemical systems operated at conversions higher than 70\%. A new criterion is proposed to calculate the minimum dilution factor to guarantee negligible gas-liquid mass transfer limitations as a function of conversion, external mass transfer and global pseudo second-order kinetics.
\end{abstract}

\begin{tabular}{|c|c|}
\hline \multicolumn{2}{|c|}{ Nomenclature } \\
\hline$a$ & Gas-liquid contact area $\left[\mathrm{m}^{2} / \mathrm{m}^{3}\right.$ reactor $]$ \\
\hline$a_{\mathrm{LS}}$ & $\begin{array}{l}\text { Effective liquid-solid contact area } \\
{\left[\mathrm{m}^{2} / \mathrm{m}^{3} \text { reactor }\right]}\end{array}$ \\
\hline $\mathrm{AR}$ & Atmospheric Residue \\
\hline$a_{\mathrm{t}}$ & $\begin{array}{l}\text { External area of particles per unit volume of } \\
\text { reactor }\left[\mathrm{m}^{2} / \mathrm{m}^{3} \text { reactor }\right]\end{array}$ \\
\hline $\mathrm{C}$ & Molar concentration $\left[\mathrm{mol} \mathrm{m}^{-3}\right]$ \\
\hline CFD & Computational Fluid Dynamics \\
\hline$D_{\mathrm{ax}}$ & Axial dispersion coefficient $\left[\mathrm{m}^{2} \mathrm{~s}^{-1}\right]$ \\
\hline$D_{\text {eff }}$ & Effective diffusion $\left[\mathrm{m}^{2} \mathrm{~s}^{-1}\right]$ \\
\hline$D_{\mathrm{m}}$ & Molecular diffusion $\left[\mathrm{m}^{2} \mathrm{~s}^{-1}\right]$ \\
\hline$D_{\mathrm{p}}$ & Particle diameter $[\mathrm{m}]$ \\
\hline$D_{\mathrm{r}}$ & Reactor diameter $[\mathrm{m}]$ \\
\hline DS & Desulfurization \\
\hline$E_{\mathrm{a}}$ & Activation energy $\left[\mathrm{J} \mathrm{mol}^{-1}\right]$ \\
\hline $\mathrm{H}$ & $\begin{array}{l}\text { Henry constant } \\
{\left[\mathrm{mol}_{\text {ogs }} \mathrm{m}^{3} \text { liguid } \mathrm{mol}^{-1} \text { liguid } \mathrm{m}^{-3}{ }_{\text {ogs }}\right]}\end{array}$ \\
\hline & liquid \\
\hline
\end{tabular}

* Corresponding author: alberto.servia@ifpen.fr

$\begin{array}{ll}\text { HDM } & \text { Hydrodemetallation } \\ \mathrm{ID} & \text { Internal Diameter } \\ k_{0} & \text { Pre-exponential factor }\left[\mathrm{mol} \mathrm{kg}^{-1} \text { catalyst } \mathrm{s}^{-1}\right] \\ K_{\mathrm{i}} & \text { Adsorption constant of species "i" }\left[\mathrm{m}^{3} \mathrm{~mol}^{-1}\right] \\ k_{\mathrm{L}} & \text { Gas-liquid mass transfer coefficient }\left[\mathrm{m} \mathrm{s}^{-1}\right] \\ k_{\mathrm{LS}} & \text { Liquid-solid mass transfer coefficient }\left[\mathrm{m} \mathrm{s}^{-1}\right] \\ \mathrm{LHSV} & \text { Liquid Hourly Space Velocity }\left[\mathrm{s}^{-1}\right] \\ \mathrm{M} & \text { Metal atom } \\ \mathrm{N} & \text { Nitrogen } \\ \mathrm{Ni} & \text { Nickel } \\ P & \text { Absolute pressure }[\mathrm{Pa}] \\ r & \text { Catalyst particle radial coordinate }[\mathrm{m}] \\ R & \text { Perfect gas constant }\left[\mathrm{J} \text { mol }{ }^{-1} \mathrm{~K}^{-1}\right] \\ \mathrm{R} \& \mathrm{D} & \text { Research and Development } \\ \mathrm{Re} & \text { Reynolds number } \\ r_{\mathrm{j}} & \text { Rate of chemical reaction " } \mathrm{j} " \\ & \left.\text { [mol kg }{ }^{-1} \text { catalyst. }{ }^{-1}\right] \\ R_{\mathrm{p}} & \text { Catalyst partice radius }[\mathrm{m}] \\ \mathrm{S} & \text { Sulfur } \\ t & \text { Time }[\mathrm{s}]\end{array}$




$\begin{array}{ll}T & \text { Temperature }[\mathrm{K}] \\ \mathrm{V} & \text { Vanadium } \\ \mathrm{VR} & \text { Vacuum residue } \\ v_{\mathrm{S}} & \text { Superficial velocity }\left[\mathrm{m} \mathrm{s}^{-1}\right] \\ X & \text { Conversion } \\ z & \text { Axial coordinate }[\mathrm{m}]\end{array}$

\section{Subscripts and superscripts}

$\begin{array}{ll}* & \text { Equilibrium conditions } \\ \text { G } & \text { Gas } \\ \text { in } & \text { Reactor inlet } \\ \text { L } & \text { Liquid } \\ \text { f } & \text { Liquid film } \\ \text { P } & \text { Particle } \\ \text { S } & \text { Solid }\end{array}$

\section{Greek symbols}

$\begin{array}{ll}\alpha & \text { Ratio between } \mathrm{H}_{2} \text { molar concentration in the } \\ & \text { gas and in the liquid phases } \\ \tau_{\mathrm{G}} & \text { Global dilution factor } \\ & {\left[\mathrm{m}^{3} \text { catalyst } \mathrm{m}^{-3} \text { catalyst+inert }\right]} \\ \tau_{\mathrm{L}} & \text { Local dilution factor }\left[\mathrm{m}^{3} \text { catalyst } \mathrm{m}^{-3} \text { catalyst+inert }\right] \\ \varepsilon_{\mathrm{i}} & \text { Relative volume of phase "ij" }\left[\mathrm{m}^{3} \mathrm{~m}^{-3} \text { reactor }\right] \\ \varepsilon_{\mathrm{P}} & \text { Catalyst particle porosity }\left[\mathrm{m}^{3} \mathrm{~m}^{-3} \text { catalyst }\right] \\ \rho & \text { Density }\left[\mathrm{kg} \mathrm{m}{ }^{-3}\right] \\ v_{\mathrm{i}, \mathrm{j}} & \text { Stoichiometric coefficient of species " } \mathrm{i} \text { " in } \\ \mu & \text { reaction " } \mathrm{j} \text { " } \\ \mu & \text { Viscosity }[\mathrm{Pa} \mathrm{s}]\end{array}$

\section{Introduction}

The exponential growth of the demand for petrochemical intermediates and the increasing market volume of heterogeneous catalysts for refinery applications ensure the attractiveness of this sector for the main world catalysts suppliers $[1,2]$. The competitiveness of this field is expected to be reinforced in the upcoming years, and consequently, new generations of catalysts with improved activity, selectivity and stability will be developed to allow catalyst suppliers to acquire or raise market shares.

The vast majority of the refining and petrochemical processes uses fixed-bed reactor technology due to its low capital cost and easy operation. Pilot and laboratory fixed-bed reactor technology has experienced a great evolution over the past half century. Lab reactor volumes have been substantially reduced from some liters to a few milliliters or even less with the high throughput experimentation [3], with highly parallelized fixed-bed reactors containing less than 100 catalyst particles. This downscaling coupled with the increasing chemical reaction rate of new catalytic formulations has triggered many studies on reactor performances, i.e. hydrodynamics, heat and mass transfer. Poor reactor performance may significantly affect the results and prevent from a reliable up-scaling.
Generally, experiments at lab scale are carried out under isothermal conditions and at the same residence time as in the industrial reactor, resulting in a constant ratio between reactor bed length and fluid velocity at both scales. Typically, lab catalytic beds are a few decimeters height whereas industrial reactors are 10-30 m long. Fluids linear velocities in lab reactors are, hence, two orders of magnitude lower than within industrial reactors, which strongly affects heat and mass transfer performances at the lab scale. Indeed, for fast and/or highly endothermic or exothermic chemical reactions, this yields important momentum, mass and/or heat mass transfer limitations in lab reactors [4]. Momentum and mass transfer limitations are often responsible for conversion decrease, selectivity modification and in some cases accelerated catalyst deactivation [5]. Heat transfer limitations result in a non-uniform temperature field that might change the reaction pathways as well as catalyst selectivity and stability. In the worst case, non-isothermal reactor operation may lead to reactor runaway for highly exothermic reactions.

Three approaches exist to guarantee the determination of the intrinsic kinetics from lab data, to be used afterwards in the design of industrial reactors. The first approach consists on operating lab reactors in the kinetically controlled regime allowing experimental results to be directly scaledup. Design criteria have been developed over the past years to minimize momentum, heat and mass transfer limitations in lab reactors [6]. Sie proposed a criterion on how to ensure a proper distribution of liquids in downflow gas-liquid fixed-bed reactors [7]. Mears [8] and Gierman [9] developed a conversion-dependent criterion to prevent from axial mass dispersion effects. Thiele proposed a criterion to account for internal mass transfer limitations [10]. Mears developed a criterion to ensure external mass transfer limitations to be minimized during heterogeneous catalyst testing [11]. More recently, Rolland and Fonte established new criteria on the minimum number of catalytic pellets to be used to ensure experiments reproducibility [12]. There is no universal rule as the optimal reactor depends on the chemical system under consideration. Furthermore, one corrective action to reduce a specific limiting phenomenon can have a negative influence on another phenomenon. An example is the reduction of the reactor diameter for radial temperature gradients elimination, which, in contrast, may increase flow mal-distribution through preferential passages.

For fast and/or highly exothermic or endothermic chemical reactions the abovementioned criteria might not be met. In that case, a second approach consists on the indirect determination of kinetics from experimental measurements through the use of mathematical models describing hydrodynamics, heat and mass transfer inside the reactor. The selection of mass and heat transfer correlations, often presenting high deviations between them and usually calibrated with data coming from cold mock-up experiments, may introduce some uncertainties in the regressed kinetic parameters.

Recently, Computational Fluid Dynamics (CFD) coupled with both mass and heat transport equations has emerged as an interesting tool to perform the direct numerical simulation of the different physics encountered in a 
pilot plant reactor with no assumptions on the physics [13-15]. However, this third approach is still limited to the calculation of small cases with around 100 particles as the mesh resolution to capture concentration gradients is beyond today's computing capabilities.

Bed dilution appears to be one of the most versatile and robust way to improve hydrodynamics and heat transfer. Adding powder finer than the catalyst helps preventing preferential paths and reduces axial dispersion effects [7-9]. Nevertheless, the coupling between high dilution factors and operation at high conversions must be avoided due to a possible catalyst misdistribution resulting in catalyst by-passing inside the reactor [16-18]. Adding the inert material can be executed by filling up the catalyst bed porosity which does not change the overall bed length or by expanding the bed length through dilution. Porosity filling can only be performed with very fine powder (50-300 $\mu \mathrm{m})$ for millimetric size pellets while dilution can be carried out with any powder size, eventually mixtures of several powder sizes. Diluting the catalyst in a highly thermal conductive material such as $\mathrm{SiC}$ or non-porous ceramics (alumina, zirconia, etc.) reduced thermal gradients [19] due to the reduction of the amount of heat generated per unit volume and to a faster heat dissipation. Regarding mass transfer, catalyst dilution is expected to improve the results through the reduction of the amount of reactive demand per unit volume of reactor, while keeping the gas-liquid transfer rate unchanged. Nevertheless, it is not likely to improve liquid-solid mass transfer as liquid-solid mass flux and reactive demand per unit reactor volume are reduced to the same extent. To the best of our knowledge, there is no work showing the benefits of catalyst dilution for mass transfer enhancement purposes. Dilution can be uniform or vary along the reactor length. It can also be performed by alternating layers of catalyst and inert material. What is the most suitable dilution method for a given application? What amount of diluent is needed? Where should it be added? In what proportion?

This paper investigates bed dilution techniques in order to intensify mass transfer within lab gas-liquid fixed-bed reactors. More precisely, this paper offers a discussion on how to decide the optimal strategy for improving reactor performance using inert material in a fixed-bed reactor in order to answer to the abovementioned inquiries.

\section{Methodology}

An isothermal 1D (one-dimensional) reactor model coupling axial mass dispersion effects, external and internal mass transfer, vapor-liquid equilibrium and kinetics was developed to study the influence of different types of dilution approaches on the performance of lab packed-bed reactors with gas-liquid mixtures flowing upwards. Dilution with powder finer than catalyst is not addressed in this work as the resulting flow is expected to be capillary [20] and mass transfer correlations for capillary flow in packed-bed reactors are not available in literature. Simulations are thus carried out by assuming the same size and shape for catalyst and inert particles. The oil residue HDM and the benzene hydrogenation are the case studies, and the coupling between simulations and experimental results is used to carry out reactor performance diagnosis and dilution method selection and optimization. The liquid reactant is the limiting species from the diffusion point of view for both applications, as suggested by the calculation of specific criteria [21], fact that justifies the selection of the upflow mode of operation. A sensitivity analysis on the oil residue HDM kinetics is performed at the end of the work for developing new criteria to ensure negligible gas-liquid mass transfer limitations as a function of conversion, external mass transfer and global pseudo second-order kinetics. The details of the dilution methods, the reactor model, the case studies and the sensitivity analysis are given in the upcoming sections.

\subsection{Dilution methods}

The different dilution approaches studied in this work are depicted in Figure 1. Both dilution methods intensify gasliquid mass transfer without modifying the role of liquidsolid mass transfer as particles size remains constant. Gas-liquid mass transfer is indeed expected to be the limiting factor as liquid-solid mass transfer is faster than the former in packed-bed reactors over a wide range of flow rates [22].

The layered dilution, in which the catalytic volume is split in one or more beds separated by inert zones, is represented in Figure 1a. The role of the inert material is to bring back the gas-liquid mixture to equilibrium conditions to compensate the gas-liquid limitations induced by the previous catalytic bed. The uniform dilution, in which catalyst particles are uniformly mixed with inert particles, is illustrated in Figure 1b. The goal is to reduce reactants consumption per unit volume of reactor while keeping the gas-liquid mass transfer performance constant. Combinations of both techniques can be interesting for specific chemical systems, as it is shown later in this paper. When discussing dilution methods, one must introduce the local dilution factor parameter $\tau_{\mathrm{L}}$, defined as the local volume fraction of catalyst within the mixture constituted by the catalyst itself and the inert material, and the global dilution factor $\tau_{\mathrm{G}}$, defined as the global volume fraction of catalyst within the entire reactor volume, defined as the space between the first and the last catalytic beds. Thus, inert beds immediately before the first catalytic bed or after the last catalytic bed are not considered in the simulation nor in the dilution factor calculation. The higher the dilution factor, the higher the reduction expected on gas-liquid mass transfer limitations.

\subsection{Reactor model}

The following assumptions are considered in order to simplify model formulation for gas-liquid packed-bed reactors operated in upflow:

- Isothermal operation.

- Negligible pressure drop.

- Ideal plug-flow for the gas phase.

- Plug-flow with axial dispersion for the liquid phase. 
a)

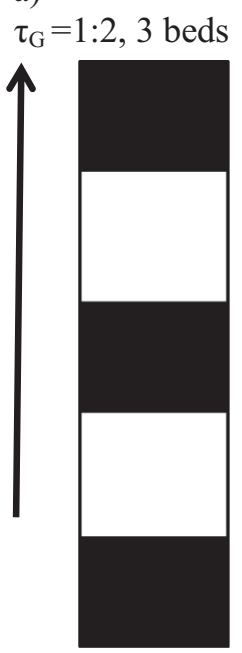

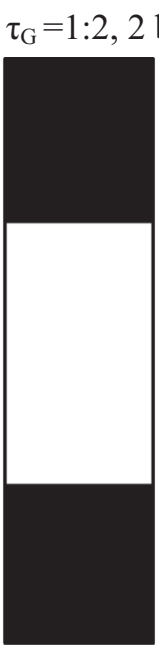

b)

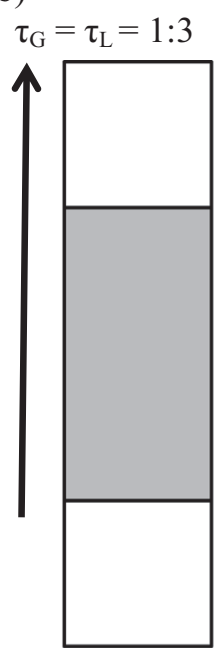

c)

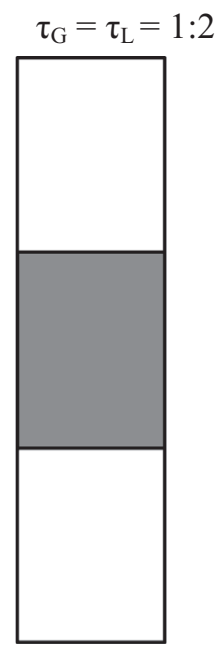

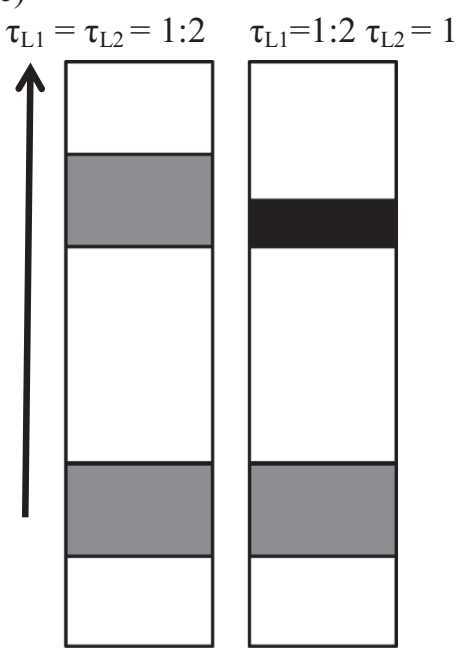

Fig. 1. Illustration of the dilution techniques considered in this work: layered dilution (a) uniform dilution (b) and combination of both (c). Black, white and grey represent catalyst, inert material and mixtures of both. The arrow represents flow direction.

- Radial concentration gradients around catalyst particles neglected.

- Constant liquid velocity.

- Constant gas, liquid and solid hold-up.

- Complete wetting conditions.

- Gas and liquid considered ideal from a thermodynamic point of view.

- Gas-liquid equilibrium at the reactor inlet.

- Catalyst particles are considered spheres with the same volume as the real catalyst particles.

Mass balance equations are solved for all the species within the gas phase (Eq. (1)), liquid phase (Eq. (2)), liquid film surrounding the catalyst particle (Eq. (3)), and within the catalyst particle itself (Eq. (4)):

$$
\underbrace{\frac{\partial C_{\mathrm{i}}^{\mathrm{G}}}{\partial t}}_{\text {Accumulation }}=-\frac{1}{\varepsilon_{\mathrm{G}}}[\underbrace{\frac{\partial\left(v_{\mathrm{S}}^{\mathrm{G}} C_{\mathrm{i}}^{\mathrm{G}}\right)}{\partial z}}_{\text {Convection }}+\underbrace{k_{\mathrm{L}}^{\mathrm{i}} a\left(\frac{C_{\mathrm{i}}^{\mathrm{G}}}{H_{\mathrm{i}}}-C_{\mathrm{i}}^{\mathrm{L}}\right)}_{\mathrm{G}-\mathrm{L} \text { transfer }}],
$$

$$
\begin{aligned}
& \underbrace{\frac{\partial C_{\mathrm{i}}^{\mathrm{L}}}{\partial t}}_{\text {Accumulation }}=-\frac{1}{\varepsilon_{\mathrm{L}}}[\underbrace{v_{\mathrm{S}}^{\mathrm{L}} \frac{\partial C_{\mathrm{i}}^{\mathrm{L}}}{\partial z}}_{\text {Convection }}-\underbrace{k_{\mathrm{L}}^{\mathrm{i}} a\left(\frac{C_{\mathrm{i}}^{\mathrm{G}}}{H_{\mathrm{i}}}-C_{\mathrm{i}}^{\mathrm{L}}\right)}_{\mathrm{G}-\mathrm{L} \text { transfer }} \\
& +\underbrace{\tau_{\mathrm{L}} \frac{k_{\mathrm{LS}}^{\mathrm{i}} \varepsilon_{\mathrm{S}} 6}{D_{\mathrm{p}}}\left(C_{\mathrm{i}}^{\mathrm{L}}-C_{\mathrm{i}}^{\mathrm{f}}\right)}_{\text {L-film transfer }}]+\underbrace{D_{\mathrm{ax}} \frac{\partial\left(\frac{\partial C_{\mathrm{i}}^{\mathrm{L}}}{\partial z}\right)}{\partial z}}_{\text {Axial dispersion }}
\end{aligned}
$$

$$
\underbrace{\frac{D_{\mathrm{i}}}{k_{\mathrm{LS}}^{\mathrm{i}}} \frac{\partial C_{\mathrm{i}}^{\mathrm{f}}}{\partial t}}_{\text {Accumulation }}=\underbrace{k_{\mathrm{LS}}^{\mathrm{i}}\left(C_{\mathrm{i}}^{\mathrm{L}}-C_{\mathrm{i}}^{\mathrm{f}}\right)}_{\mathrm{L}-\text { film transfer }}-\underbrace{\left.D_{\text {eff }}^{\mathrm{i}} \frac{\partial C_{\mathrm{i}}^{\mathrm{P}}}{\partial r}\right|_{r=R_{\mathrm{p}}}}_{\text {Catalyst diffusion }},
$$

$$
\underbrace{\varepsilon_{\mathrm{P}} \frac{\partial C_{\mathrm{i}}^{\mathrm{P}}}{\partial t}}_{\text {Accumulation }}=\underbrace{\frac{1}{r^{2}} \frac{\partial\left(D_{\text {eff }}^{\mathrm{i}} r^{2} \frac{\partial C_{\mathrm{i}}^{\mathrm{P}}}{\partial r}\right)}{\partial r}}_{\text {Catalyst diffusion }}+\underbrace{\sum_{\mathrm{i}, \mathrm{j}} \mathrm{v}_{\mathrm{i}, \mathrm{j}} r_{\mathrm{j}} \rho_{\mathrm{s}}}_{\text {Kinetics }} .
$$

The gas velocity changes due to $\mathrm{H}_{2}$ consumption and constant pressure operation. The sum of the different mass balances within the gas phase and the expression of the total gas concentration as a function of pressure and temperature through the perfect gas law allow gas velocity to be computed as a function of reactor height:

$$
\underbrace{\frac{\partial\left(v_{\mathrm{S}}^{\mathrm{G}} \frac{P}{R T}\right)}{\partial z}}_{\text {Convection }}=-\underbrace{\sum_{\mathrm{i}} k_{\mathrm{L}}^{\mathrm{i}} a\left(\frac{C_{\mathrm{i}}^{\mathrm{G}}}{H_{\mathrm{i}}}-C_{\mathrm{i}}^{\mathrm{L}}\right)}_{\mathrm{G}-\mathrm{L} \text { transfer }} .
$$

The solution of the partial differential equations system abovementioned needs the establishment of boundary conditions for the stationary solution. Both gas and liquid concentrations at the reactor inlet respect thermodynamic equilibrium (Eqs. (6) and (7)). Both inlet and outlet are closed to axial dispersion effects (Eq. (8)). For the resolution of the diffusion-reaction equation for each species, two boundary conditions are needed. The first one is the symmetrical condition at the particle center (Eq. (9)), whereas the second one is the continuity of mass fluxes at the external surface (Eq. (10)):

$$
\begin{gathered}
C_{\mathrm{i}}^{\mathrm{G}}(z=0)=C_{\mathrm{i}}^{\mathrm{G}, *}, \\
C_{\mathrm{i}}^{\mathrm{L}}(z=0)=C_{\mathrm{i}}^{\mathrm{L}, *}, \\
C_{\mathrm{i}}^{\mathrm{L}}(z=0)=C_{\mathrm{i}, \text { in }}^{\mathrm{L}}+\frac{D_{\mathrm{ax}}}{v_{\mathrm{S}}^{\mathrm{L}}} \frac{\partial C_{\mathrm{i}}^{\mathrm{L}}}{\partial z}(z=0) ;-D_{\mathrm{ax}} \frac{\partial C_{\mathrm{i}}^{\mathrm{L}}}{\partial z}(z=L)=0,
\end{gathered}
$$




$$
\begin{gathered}
\left.D_{\text {eff }}^{\mathrm{i}} \frac{\partial C_{\mathrm{i}}^{\mathrm{P}}}{\partial r}\right|_{r=0}=0 \\
k_{\mathrm{LS}}^{\mathrm{i}}\left(C_{\mathrm{i}}^{\mathrm{L}}-C_{\mathrm{i}}^{\mathrm{f}}\right)=\left.D_{\text {eff }}^{\mathrm{i}} \frac{\partial C_{\mathrm{i}}^{\mathrm{P}}}{\partial r}\right|_{r=R_{\mathrm{p}}} .
\end{gathered}
$$

Gas-liquid equilibrium constants for the different species were computed from flash calculations at constant pressure and temperature performed in ProII 10.1.

Liquid-solid and gas-liquid mass transfer coefficients were determined by the correlations from the works of Goto et al. [22] and Saada [23] based on the recommendations from the review of Larachi et al. [24]. Related equations along with the validation ranges are given below. Both correlations were obtained under laminar conditions in the upflow mode of operation, conditions that match the operating conditions used during the experiments of this work.

$$
\begin{gathered}
J_{\mathrm{D}}=1.31\left(\operatorname{Re}_{\mathrm{L}}\right)^{-0.436} \text { with } J_{\mathrm{D}}=\frac{k_{\mathrm{LS}} a_{\mathrm{LS}}}{a_{\mathrm{t}}}\left(\frac{1}{v_{\mathrm{SL}}}\right)\left(\frac{\mu_{\mathrm{L}}}{\rho_{\mathrm{L}} D_{\mathrm{m}}}\right)^{2 / 3} \\
\left(0.2<\operatorname{Re}_{\mathrm{L}}<20\right), \\
\mathrm{Sh}=\frac{k_{\mathrm{L}} a d_{\mathrm{p}}^{2}}{D_{\mathrm{m}}}=10.72 \operatorname{Re}_{\mathrm{G}}^{0.22} \operatorname{Re}_{\mathrm{L}}^{0.32}\left(\frac{D_{\mathrm{p}}}{D_{\mathrm{R}}}\right)^{0.33} \\
\left(4<\operatorname{Re}_{\mathrm{L}}<105\right) ;\left(20<\operatorname{Re}_{\mathrm{G}}<450\right) .
\end{gathered}
$$

Liquid axial dispersion values were computed from Belfares et al. [25]. Liquid hold-up was obtained from the correlation of Bensetiti et al. [26] calibrated with an experimental database of 1322 points from experiments carried out in upflow. Both correlations mentioned before are not presented here as they have been directly coded within the flooded-bedsimulator developed by the Université de Laval, Canada. The conditions used during the experiments of this work fall within the validation range of both correlations. Diffusion coefficients were calculated with the well-known WilkeChang equation [27], for which molar volume at normal boiling point for the diffusing species is needed, and computed from the equation of Le Bas [27]. All other properties such as liquid and gas density and viscosity, and liquid surface tension, except for residue viscosity, calculated with an in-house correlation, were computed from ProII 10.1 simulations.

The system of differential equations along with the different physico-chemical properties is implemented in Fortran and the equations are discretized by using the explicit finite differences method with the central difference scheme for second order derivatives. Sensitivity analysis is performed to guarantee grid-independent numerical simulations results. Hundred elements were considered in the axial direction, whereas 30 elements were used for discretizing the catalyst particle. All grid points are equidistant between them.

\subsection{Case studies}

Experiments used for kinetic parameters regression and for reactor performance diagnosis as well as the different dilution strategies numerically evaluated are presented for both case studies in the following section.

\subsubsection{Oil residue Hydrodemetallation (HDM)}

Oil atmospheric or vacuum residue contains important amounts of impurities such as Ni, V, S and N. The removal of the metal content from these feedstocks is mandatory as these species act as poisons of downstream catalysts. This removal is carried out in the first catalytic bed of the Atmospheric/Vacuum Residue Desulfurization (ARDS/ VRDS) process, in which the oil residue is hydrotreated under high hydrogen pressures of around 200 bar. The coupling between very low liquid velocities (liquid hourly space velocities - LHSV are in between 0.4 and $1.5 \mathrm{~h}^{-1}$ ) and significant liquid viscosities, depending on the crude origin, may introduce mass transfer limitations at the lab scale. The lab HDM reactor has a $3.6 \mathrm{~cm}$ internal diameter and contains a thermowell with $6.5 \mathrm{~mm}$ external diameter placed in the middle of the reactor for temperature control purposes. Thermal effects are neglected from temperature profiles evaluation. Catalyst particles with an equivalent diameter of $2.2 \mathrm{~mm}$ are loaded within the reactor without dilution.

The HDM chemical reaction is given by the following equation:

$$
\begin{gathered}
\mathrm{C}_{49} \mathrm{H}_{71} \mathrm{~S}_{1.1} \mathrm{~N}_{0.2} \mathrm{O}_{0.1} \mathrm{M}_{0.0021}+6.28 \mathrm{H}_{2} \rightarrow 2 \mathrm{C}_{24.5} \mathrm{H}_{41} \mathrm{~S}_{0.3} \mathrm{~N}_{0.02} \mathrm{O}_{0.03} \\
\quad+0.5 \mathrm{H}_{2} \mathrm{~S}+0.04 \mathrm{H}_{2} \mathrm{O}+0.16 \mathrm{NH}_{3}+0.0021 \mathrm{M}
\end{gathered}
$$

The molecular formula of the two lumps (boiling points above and below $520^{\circ} \mathrm{C}$ ) considered for the HDM chemical reaction are determined by using simulated distillation, elemental analysis for each lump and average molecular weight data for each lump. No distinction is considered between the reactivity of $\mathrm{Ni}$ and $\mathrm{V}(\mathrm{M}-$ metal $)$, and they are supposed to be contained within molecules presenting boiling points above $520{ }^{\circ} \mathrm{C}$. Finally, the reaction scheme assumes that the metal molecule hydrodemetallation is accompanied by a cracking reaction.

The kinetic law is calibrated for reaction order of the metal-containing reactivity family $\left(520{ }^{\circ} \mathrm{C}^{+}\right)$and pre-exponential factor determination purposes. Five experimental tests are used for model calibration, at constant temperature of $370{ }^{\circ} \mathrm{C}$, pressure of $140 \mathrm{bar}, \mathrm{H}_{2} /$ hydrocarbon of $1000 \mathrm{NL} / \mathrm{L}$ and at LHSV's ranging from 0.45 to $1.2 \mathrm{~h}^{-1}$. The feed is a mixture of $70 \%$ of Atmospheric Residue (AR) and $30 \%$ of Vacuum Residue (VR) in a mass basis. The resulting kinetic-law expression for the residue $\mathrm{HDM}$ is given by the following equation:

$$
\begin{aligned}
r_{\mathrm{HDM}}= & 5.72 \exp \left(-\frac{125000}{R T}\right)\left(C_{\mathrm{C}_{49} \mathrm{H}_{71} \mathrm{~S}_{1.1} \mathrm{~N}_{0.2} \mathrm{O}_{0.1} \mathrm{M}_{0.0021}}^{\mathrm{p}}\right)^{1.1} \\
& \times \mathrm{C}_{\mathrm{H}_{2}}^{\mathrm{p}} \mathrm{H}_{\mathrm{H}_{2}} .
\end{aligned}
$$




\section{a) Layered dilution}

$\tau_{\mathrm{G}} 1: 2-1: 3$, two catalytic beds


$\tau_{\mathrm{G}} 1: 2,2-5$ catalytic beds


b) Uniform dilution, $\tau_{\mathrm{G}}=\tau_{\mathrm{L}}=1: 2-1: 6$
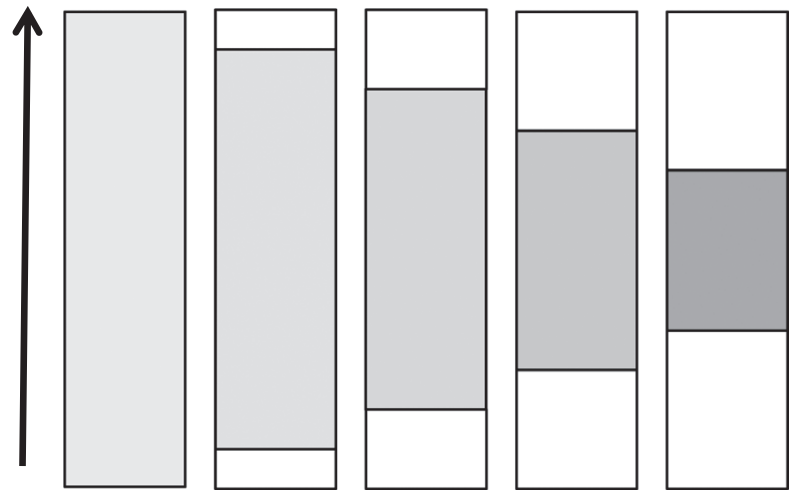

Fig. 2. Loading methods numerically tested for the HDM lab reactor case study. The arrow represents flow direction.

The different dilution techniques numerically tested for gas-liquid mass transfer intensification purposes for that specific case study are illustrated in Figure 2. Two strategies are considered in the case of layered dilution: only one inert bed with different global dilution factors or one constant global dilution factor of 1:2 with two or more inert beds (Fig. 2a). Regarding the uniform dilution technique, dilution factors between 1:2 and 1:6 are simulated (Fig. 2b). One should note that catalyst height is not kept constant between figures for illustration simplification purposes. Nevertheless, the catalyst volume is kept constant for all simulations and equal to the catalyst volume of the standard experiments without dilution.

\subsubsection{Benzene hydrogenation}

Cyclohexane, which is an intermediate in nylon production, is usually produced from benzene under moderate hydrogen pressures of around 20 bar on Ni-containing catalysts. Unlike the previous case, benzene hydrogenation is carried out at high LHSV due to the high benzene hydrogenation reaction rate. Benzene hydrogenation is a fast chemical reaction and consequently, it is likely to be affected by mass transfer limitations, especially within small lab reactors in which catalyst screening is for instance carried out. One should note that the aim of catalyst screening is to ensure a reliable catalyst ranking as well as enough difference in catalytic performances to justify candidate selection and further developments. Experiments are carried out in a $10.2 \mathrm{~mm}$ ID (Internal Diameter) reactor with an oil circulation within a double jacket surrounding the reactor to guarantee isothermal operation, confirmed from experimental evidence. Reactors are loaded either with catalyst A, with an equivalent diameter of $2.5 \mathrm{~mm}$, or with catalyst $\mathrm{B}$, with an equivalent diameter of $1.2 \mathrm{~mm}$. Two catalyst beds are separated by a $9.5 \mathrm{~cm}$ long inert bed and diluted with 3 volumes of $\mathrm{SiC}\left(\tau_{\mathrm{L} 1}=\tau_{\mathrm{L} 2}=1: 4\right)$.

The kinetic law expression for this chemical reactions is taken from the work of Toppinen et al. [28]:

$$
r_{\mathrm{BZ}}=\frac{k_{0} \exp \left[-\frac{E_{\mathrm{a}}}{R}\left(\frac{1}{T}-\frac{1}{373.15}\right)\right] K_{\mathrm{BZ}} C_{\mathrm{BZ}}^{\mathrm{p}} K_{\mathrm{H}_{2}} C_{\mathrm{H}_{2}}^{p}}{\left(3 K_{\mathrm{BZ}} C_{\mathrm{BZ}}^{\mathrm{p}}+\left(K_{\mathrm{H}_{2}} C_{\mathrm{H}_{2}}^{\mathrm{p}}\right)^{0.5}+1\right)^{3}} .
$$

Experiments with a model feed containing $1 \%$ of benzene in $n$-heptane in a mass basis at a LHSV of $40 \mathrm{~h}^{-1}$, pressure of 30 bar, $\mathrm{H}_{2}$ /benzene of $250 \mathrm{NL} / \mathrm{L}$ and at temperatures ranging from 95 to $140{ }^{\circ} \mathrm{C}$ are used for pre-exponential factor calibration of catalyst A. Catalyst B pre-exponential factor is determined by assuming a linear correlation between this parameter and the catalyst metal content of both catalysts. The resulting kinetic parameters are given in Table 1. Activation energy and adsorption constants are taken from 
Table 1. Kinetic parameters of the benzene hydrogenation kinetic law.

\begin{tabular}{lcc}
\hline & Catalyst A & Catalyst B \\
\hline$k_{0}[\mathrm{~mol} /(\mathrm{kg} \mathrm{s})]$ & 2 & 3 \\
$E_{\mathrm{a}}[\mathrm{kJ} / \mathrm{mol}]$ & 53.9 & 53.9 \\
$K_{\mathrm{BZ}} \times 10^{4}\left[\mathrm{~m}^{3} / \mathrm{mol}\right]$ & 18.3 & 18.3 \\
$K_{\mathrm{H} 2} \times 10^{4}\left[\mathrm{~m}^{3} / \mathrm{mol}\right]$ & 7074.5 & 7074.5 \\
\hline
\end{tabular}

a literature work [28] performed on a catalytic formulation equivalent to Catalyst A. The pre-exponential factor regressed for catalyst A from experimental data is close to the one reported in literature [28], result expected accounting for the similarity of both catalytic formulations.

The effect of dilution is tested by considering the simulation of a non-diluted bed for both catalysts as represented in Figure 3a. Different dilution approaches (Figs. 3b-3d) are also evaluated to gain insight on dilution interest for fast chemical reactions operated at conversions higher than in the case of the oil residue hydrodemetallation. The layered dilution with a global dilution factor of $1: 2$ is considered in Figure 3b whereas the uniform dilution with dilution factors ranging from 1:2 to $1: 4$ is illustrated in Figure 3c. Finally, combinations of both dilution techniques are also evaluated for this specific case (Fig. 3d), since the initial experiments submitted to diagnosis are performed by using this particular configuration. The inert bed separating the uniformly diluted catalyst beds is kept constant for all simulations and equal to $9.5 \mathrm{~cm}$. Uniform dilutions between $1: 2$ and 1:4 are considered at the catalyst bed inlet, outlet and both, as represented in Figure 3d. One should note, as for the HDM case study, that representations are given for illustration simplification purposes, and they do not exactly represent the actual beds dimensions. The catalyst volume remains constant for all simulations.

\subsection{Sensitivity analysis}

The sensitivity analysis consists on increasing the oil residue hydrodemetallation kinetics by a factor of 5 and 10 and performing simulations for local dilution factors in the uniform dilution configuration ranging from 1:2 to 1:51 (no gas-liquid mass transfer limitations) at four different levels of conversion: $35,56,78$ and $89 \%$. The goal of this analysis is to determine the minimum local dilution factor, a) No dilution

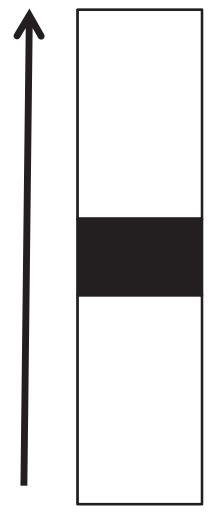

b) Layered dilution $\tau_{\mathrm{G}}=1: 2$

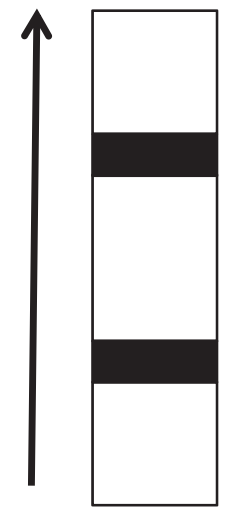

c) Uniform $\tau_{\mathrm{G}}=\tau_{\mathrm{L}}=1: 2-1: 4$

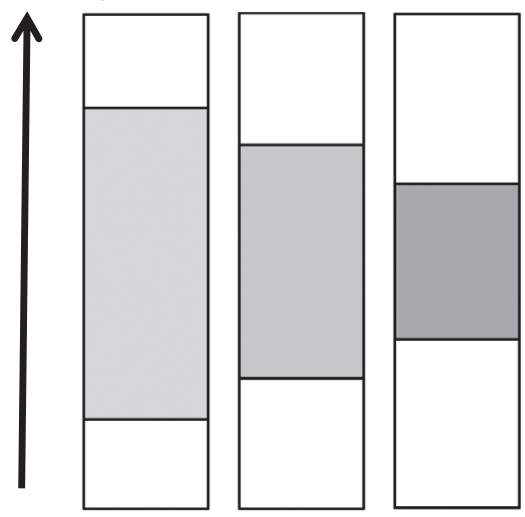

d) Combinations, inert bed of $9 \mathrm{~cm}$

Uniform $\tau_{\mathrm{L} 1}=1: 2-1: 4 \tau_{\mathrm{L} 2}=1$
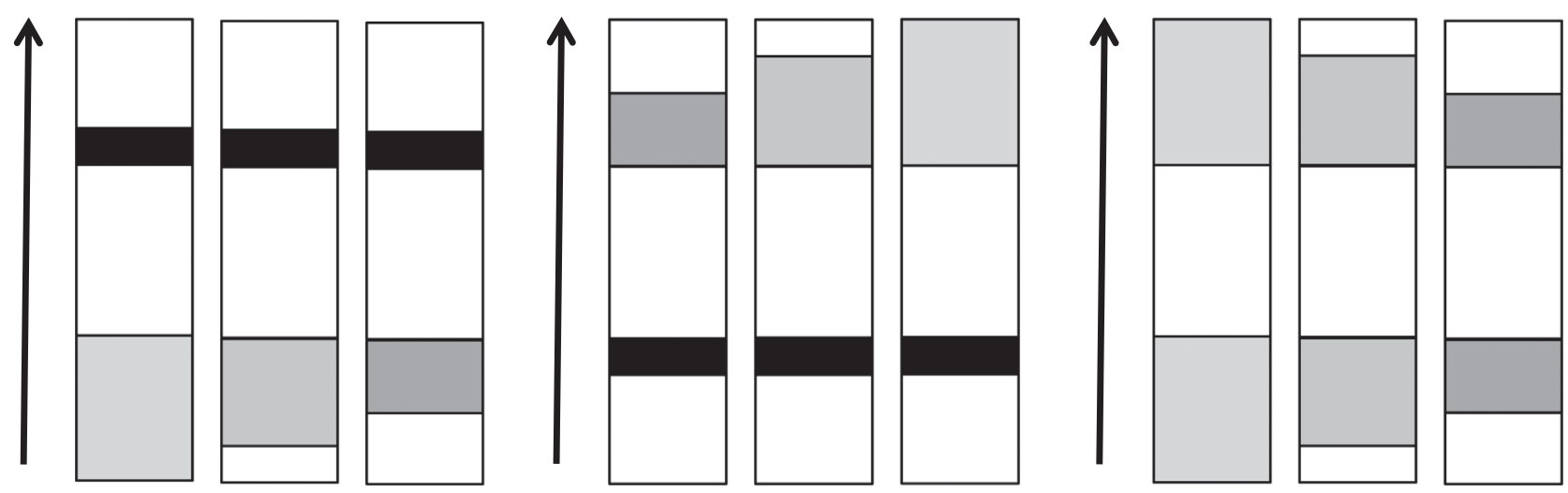

Fig. 3. Loading methods numerically tested for the benzene hydrogenation lab reactor case study. The arrow represents flow direction. 
defined as the dilution factor necessary to reach 33, 53.4, 75.5 and $87.1 \%$ conversion respectively for the previous conversion values, computed from simulations at a dilution factor of 1:51. The target conversions are calculated by imposing the temperature of the initial simulation minus the typical uncertainty of catalytic activity measurements, which is equal to $2^{\circ} \mathrm{C}$. All simulations were carried out by assuming no liquid-solid mass transfer limitations for the $520{ }^{\circ} \mathrm{C}^{+}$cut. Based on the results obtained, a new criterion based on measurable variables is proposed to guarantee gas-liquid mass transfer limitations minimization as a function of external mass transfer, global pseudo second-order kinetics and conversion.

\section{Results}

This section presents the results in terms of model calibration and concentration fields with and without catalyst dilution for each of the abovementioned case studies as well as the sensitivity analysis for the development of criteria on the minimum necessary dilution factor for ensuring negligible gas-liquid mass transfer limitations.

\subsection{Oil residue HDM}

The parity plot between experimental and simulation results is illustrated in Figure 4 in terms of HDM conversion. A good agreement exists between experimental and model data, which allows the numerical experiments to be carried out. The considerations made hereinafter for one specific experiment can be translated to the other experiments.

Liquid interface, liquid and film normalized profile concentrations for the two reactants, $\mathrm{H}_{2}$ and $520{ }^{\circ} \mathrm{C}^{+}$, are represented as a function of the normalized axial coordinate in Figure 5 . The $520^{\circ} \mathrm{C}^{+}$liquid concentration is practically equal to the $520^{\circ} \mathrm{C}^{+}$liquid interface concentration, which means that gas-liquid mass transfer is not limiting for this lump. This is explained by the low volatility of this family of compounds, that preferably remains in the liquid phase. Hydrogen behavior is completely different, presenting a significant depletion in the liquid phase immediately after the reactor inlet, due to its fast consumption at the beginning of the reactor. One should remind that each mol of $520{ }^{\circ} \mathrm{C}^{+}$ requires $6.28 \mathrm{~mol}$ of hydrogen to react. The ratio between $\mathrm{H}_{2}$ and $520{ }^{\circ} \mathrm{C}^{+}$molar concentrations at the reactor inlet is equal to 0.4 , which clearly shows the need for hydrogen dissolution to reach experimental conversions between $50 \%$ and $75 \%$. Hydrogen liquid concentration passes through a minimum and then increases as the reaction proceeds. Equilibrium conditions for hydrogen are never achieved as conversion remains at a moderate value of $60 \%$. Species concentration in the liquid phase and in the liquid film for $\mathrm{H}_{2}$ and $520^{\circ} \mathrm{C}^{+}$are close indicating moderate liquid-solid mass transfer limitations. Thus, and concerning only external mass transfer limitations, the experiments are mainly limited by $\mathrm{H}_{2}$ dissolution.

The synthesis of the results obtained from the simulation of the dilution methods exposed in Section 2.3 is

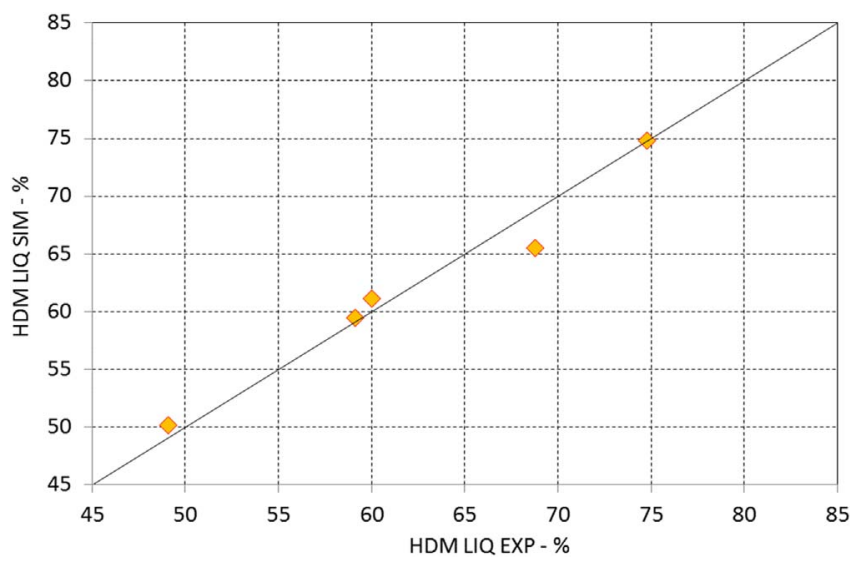

Fig. 4. Parity plot between experimental and simulated HDM conversions.

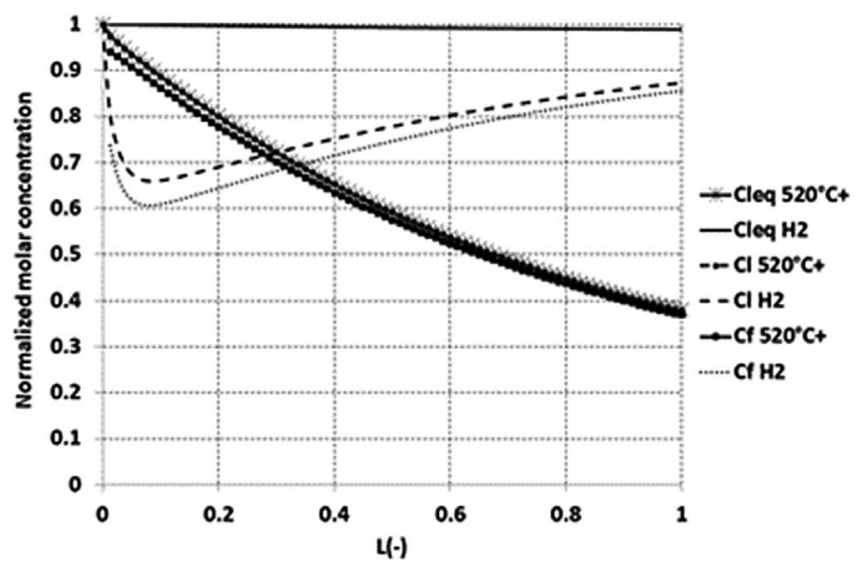

Fig. 5. Liquid interface, liquid and film normalized concentrations field for $\mathrm{H}_{2}$ and $520^{\circ} \mathrm{C}^{+}$as a function of the normalized axial coordinate.

presented in Figure 6 for the layered dilution with increasing global dilution factor and catalyst beds number and in Figure 7 for the uniform dilution with increasing dilution factor. Layered dilution with increasing dilution factor and two catalytic beds does not improve gas-liquid mass transfer despite the fast dissolution of hydrogen to reach equilibrium conditions in the inert bed (Figs. 6a and 6f). Immediately after the inert bed, gas-liquid mass transfer limitations take place as hydrogen is sharply depleted in the liquid phase. The increase of the inert bed size does not enhance results due to the low dissolution characteristic time of hydrogen compared to the liquid residence time in this zone (Fig. 6b). Results of catalyst bed split into 3-5 catalytic beds with inert beds in between are illustrated in Figures $6 \mathrm{c}-6 \mathrm{e}$. These simulations allow the determination of the necessary inert bed length for ensuring equilibrium conditions for hydrogen, as illustrated in Figure 6e.

Uniform dilution strongly decreases the relative rate of hydrogen consumption compared to its dissolution, as shown by Figure $7 \mathrm{a}-7 \mathrm{c}$. A simple dilution of 1:2 reduces hydrogen consumption per unit volume of reactor by a 
a) $\tau_{\mathrm{G}}=1: 2,2$ catalytic beds

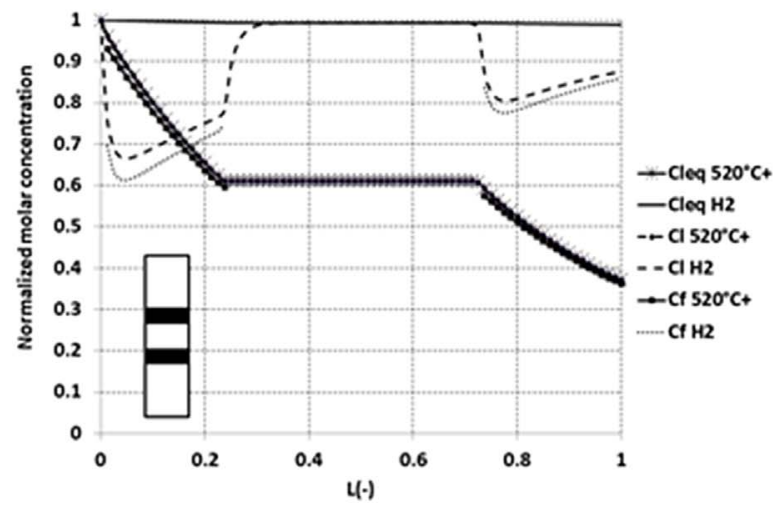

c) $\tau_{\mathrm{G}}=1: 2,3$ catalytic beds



e) $\tau_{\mathrm{G}}=1: 2,5$ catalytic beds

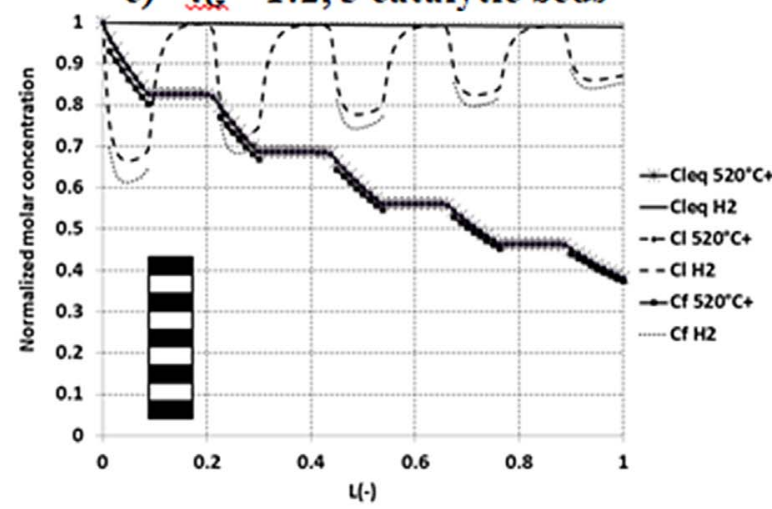

b) $\tau_{G}=1: 3,2$ catalytic beds

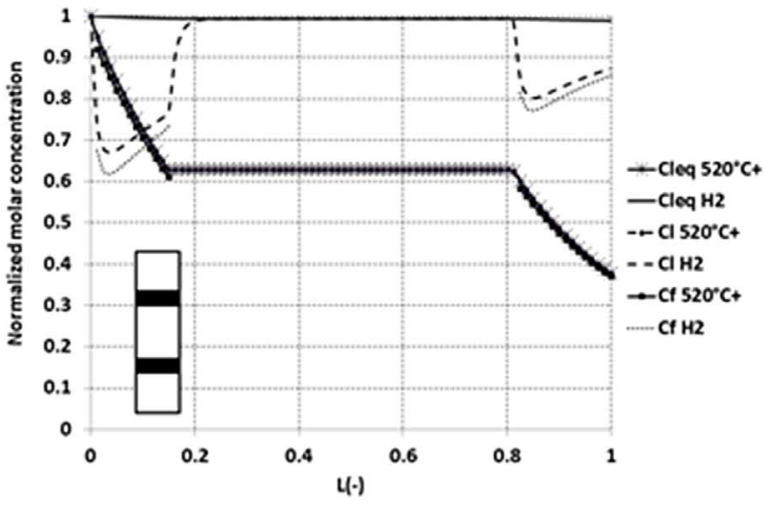

d) $\tau_{\mathrm{G}}=1: 2,4$ catalytic beds

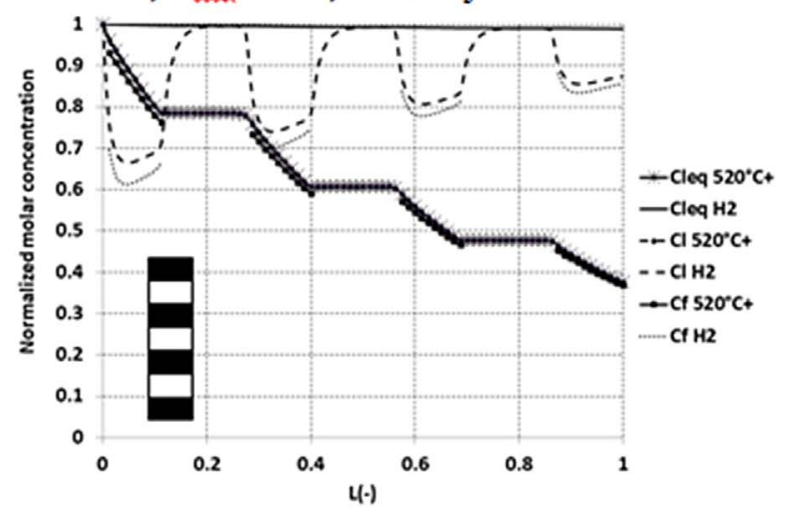

f) HDM conversion

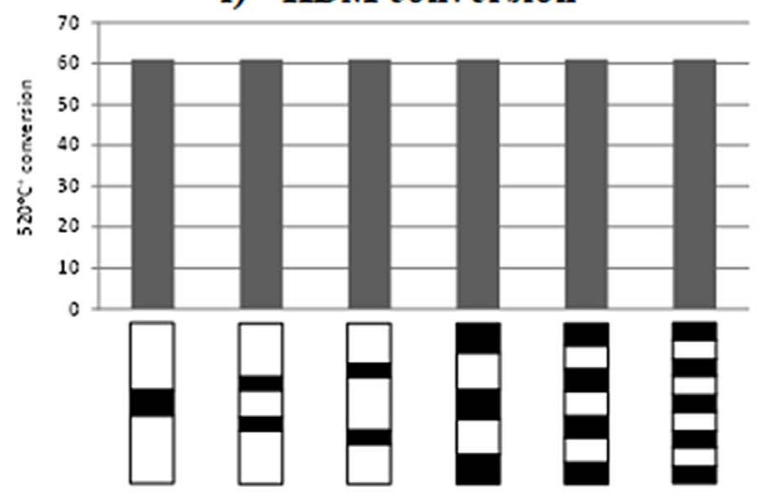

Fig. 6. Layered dilution with increasing global dilution factor and increasing number of catalytic beds effect on gas-liquid mass transfer and on HDM conversion.

factor of 2, while mass transfer rate is kept constant. That is traduced by a reduction on hydrogen depletion in the liquid phase from more than $30 \%$ for the non-diluted standard case to $20 \%$ (Fig. 7a) of the theoretical equilibrium concentration. This effect is equivalent to multiply the gas-liquid mass transfer coefficient by a factor of 2 and thus liquid velocity by 4 , since in a laminar flow, the Sherwood number is expected to be proportional to the square root of the superficial velocity [29]. The impact on HDM conversion is notorious, as conversion is increased by 3 points from $61 \%$ to $64 \%$ (Fig. $7 \mathrm{~d}$ ). The same trend is observed when increasing dilution factor, nevertheless, the impact becomes lower as equilibrium conditions are approached in the whole reactor (Figs. $7 \mathrm{~b}$ and $7 \mathrm{c}$ ). The evolution of the HDM conversion as a function of dilution factor in the uniform dilution approach, represented in Figure $7 \mathrm{~d}$ suggests that conversion can be increased from $61 \%$ to $66 \%$ by applying a dilution factor of 1:4, considered as optimal as higher dilution factors benefits may not be noticeable due to experimental uncertainties.

HDM conversions for the initial loading, the optimized dilution strategy (uniform dilution with dilution factor 1:4) and theoretical loadings without gas-liquid and gas-liquid/liquid-solid mass transfer limitations are 
a) $\tau_{\mathrm{G}}=\tau_{\mathrm{L}}=1: 2$

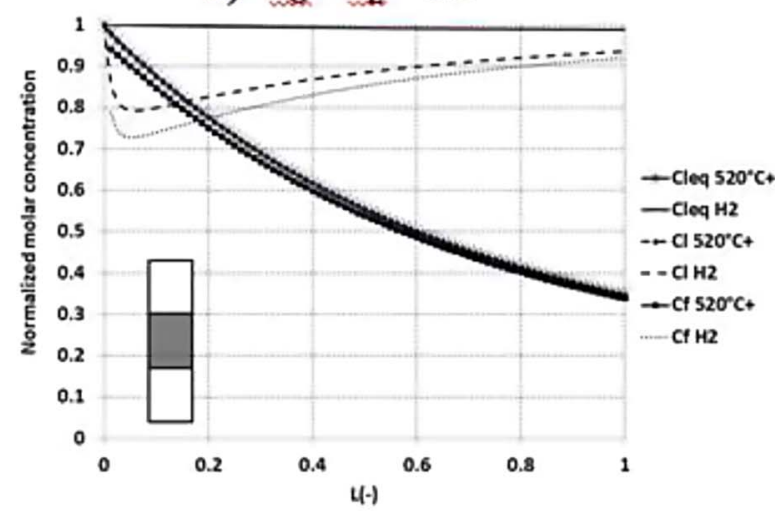

c) $\tau_{\mathrm{G}}=\tau_{\mathrm{L}}=1: 6$



b) $\tau_{\mathrm{G}}=\tau_{\mathrm{L}}=1: 4$



d) HDM conversion

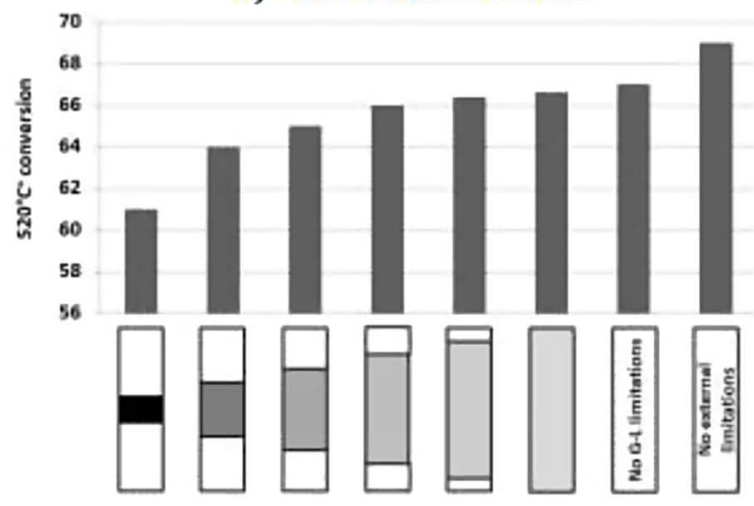

Fig. 7. Uniform dilution with increasing dilution factor effect on gas-liquid mass transfer and on HDM conversion.

presented in Figure $7 \mathrm{~d}$. The selected dilution technique approaches the theoretical loading with no gas-liquid mass transfer limitations, with a conversion difference of 1 point, which is well below the experiments uncertainty. When compared to the ideal case without any mass transfer limitations as expected in the industrial scale, the conversion difference is predicted at three points, which is approximately equal to the experiments reproducibility. Thus, using the uniform dilution method with a dilution factor of 1:4 performed with particles of the same size as the catalyst allows the experimental data to be directly scaled-up and used for industrial reactor design purposes.

\subsection{Benzene hydrogenation}

Benzene molar fraction at the reactor outlet is represented as a function of temperature for both catalysts together with model predictions in Figure 8. Model predictions are in quite good agreement with experimental results, leading to the validation of the dilution modeling approach.

Liquid interface and liquid concentration profiles as a function of the reactor axial coordinate are represented for $\mathrm{H}_{2}$ and benzene and for both catalysts in Figures 9a and $9 \mathrm{~b}$ at $140{ }^{\circ} \mathrm{C}$, conditions under which mass transfer resistance is more pronounced. A small gas-liquid mass transfer limitation can be observed for $\mathrm{H}_{2}$ for both catalysts at the reactor inlet as the chemical reaction rate is the

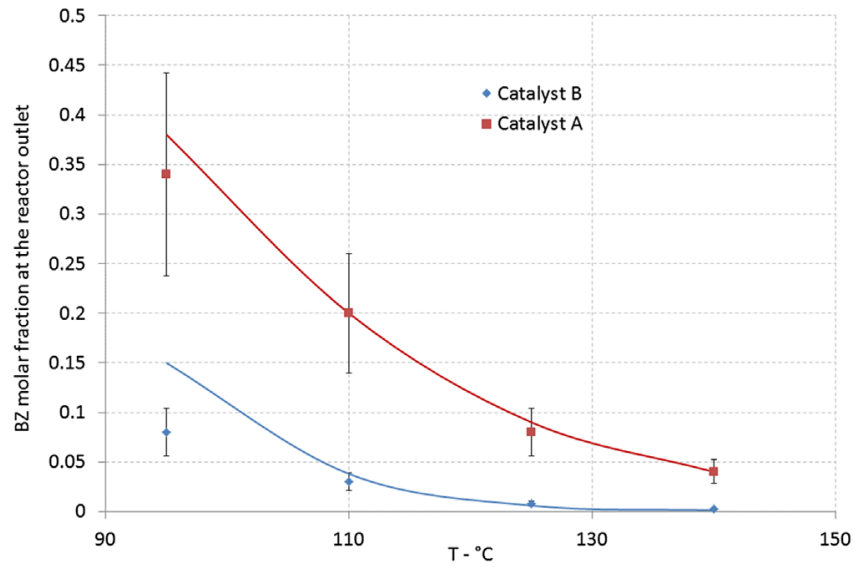

Fig. 8. Experimental and numerical benzene molar fraction results at the reactor outlet as a function of temperature for catalysts A and B. A relative uncertainty of $30 \%$ on the obtained benzene molar concentration is considered.

fastest in this point. Catalyst B is more limited by external mass transfer than catalyst $\mathrm{A}$ as it contains more $\mathrm{Ni}$ and has a smaller diameter. Even if not presented here, experiments were subject to important internal mass transfer limitations, with determined catalyst effectiveness in the range of $30 \%-50 \%$, in agreement with catalyst effectiveness 
a) Catalyst $\mathbf{A}$

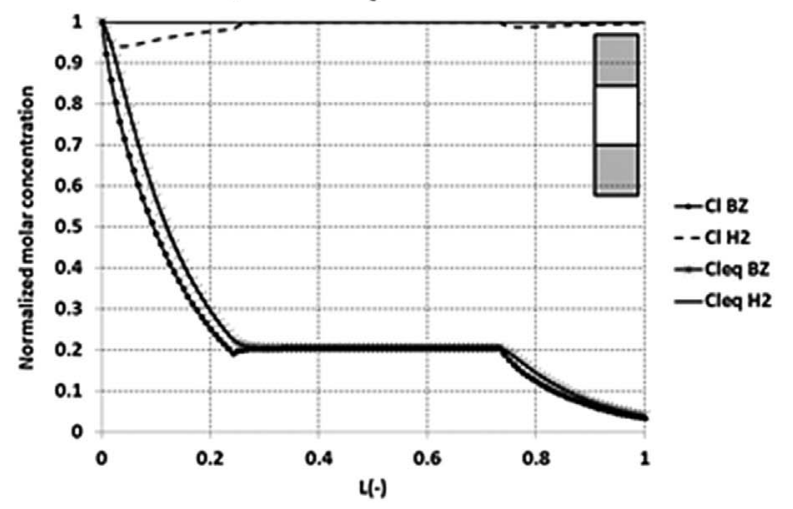

b) Catalyst $B$

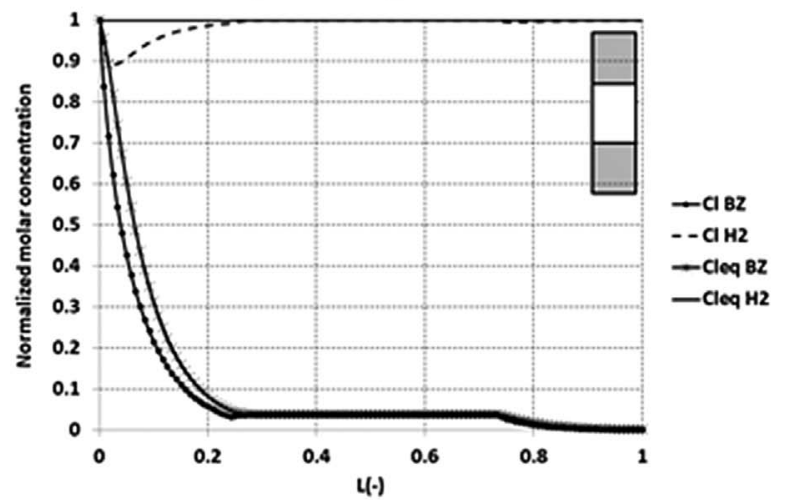

c) Residual benzene molar concentration

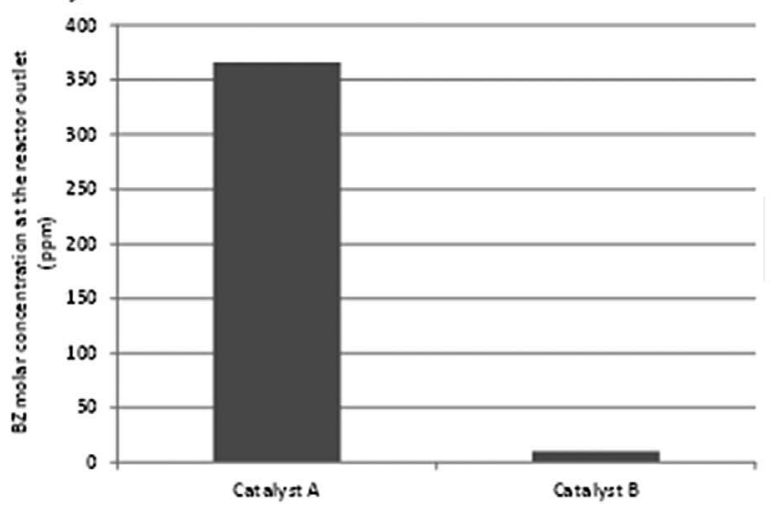

Fig. 9. Liquid interface and liquid normalized concentrations profile for hydrogen and benzene as a function of the normalized reactor axial coordinate for diluted catalyst and residual benzene at the reactor outlet for both catalysts at $140{ }^{\circ} \mathrm{C}$.

measurements not presented in this paper. The gas-liquid mass transfer limitation is lower in the second catalytic bed, as the chemical reaction is almost completed at this point and $\mathrm{H}_{2}$ demand greatly reduced. Unlike the HDM experiments, gas-liquid limitations also affect benzene as this compound is volatile. The impact is nevertheless less pronounced than for hydrogen, as three molecules of the later are required per molecule of benzene for the reaction to be carried out. All abovementioned considerations allow to conclude that the dilution approach used in this case is satisfactory since the expected performance difference is obtained from the experiments (Fig. 9c). Furthermore, these experiments can be used directly for scale-up purposes, as liquid deviation from equilibrium conditions does not exceed $10 \%$.

The direct influence of catalyst dilution is illustrated in Figure 10 through the simulation of the undiluted catalyst in one single bed. The undiluted bed loading guarantees a reliable catalyst screening even if the differences between apparent catalysts performances are lower than in the previous case due to significant gas-liquid mass transfer limitations for both species. One should keep in mind that catalyst screening can sometimes be performed between similar catalytic formulations. The difference in performance for close catalytic formulations can easily be suppressed by gasliquid mass transfer limitations and dilution should thus be practiced in that case. Furthermore, the development of a new catalytic formulation is often driven by a particular specification, that can be for instance the achievement of a given concentration at the reactor outlet under constant operating conditions. In our case, one can imagine that the catalyst provider should develop a new catalytic formulation allowing to achieve $10 \mathrm{ppm} \mathrm{mol} / \mathrm{mol}$ of benzene or less in the effluent under screening conditions. In the case under study, catalyst $\mathrm{B}$, which intrinsically allows the specification to be met, gives an effluent containing $70 \mathrm{ppm} \mathrm{mol} / \mathrm{mol}$ of benzene without dilution. Catalyst B is hence not expected to capture the catalyst supplier attention, who may intensify R\&D efforts to find a good candidate, despite it intrinsically meets the requirements.

The impact of several reactor loading configurations on the performance measurements of catalyst B is shown hereinafter. From now on, catalyst A is left out of the analysis, since all dilution techniques are expected to be able to perform catalyst screening from the abovementioned considerations. The goal of this analysis is to find a way to optimize and potentially simplify, reactor loading for accelerating catalyst screening.

The single layered dilution enhances gas-liquid mass transfer in that case as illustrated in Figure 11a, probably due to a quite high experimental conversion. Uniform dilution drastically reduces gas-liquid mass transfer limitations, even without the inert bed splitting consecutive catalytic beds, as seen in Figure 11b. A dilution factor of 
a) Catalyst $\mathbf{A}$

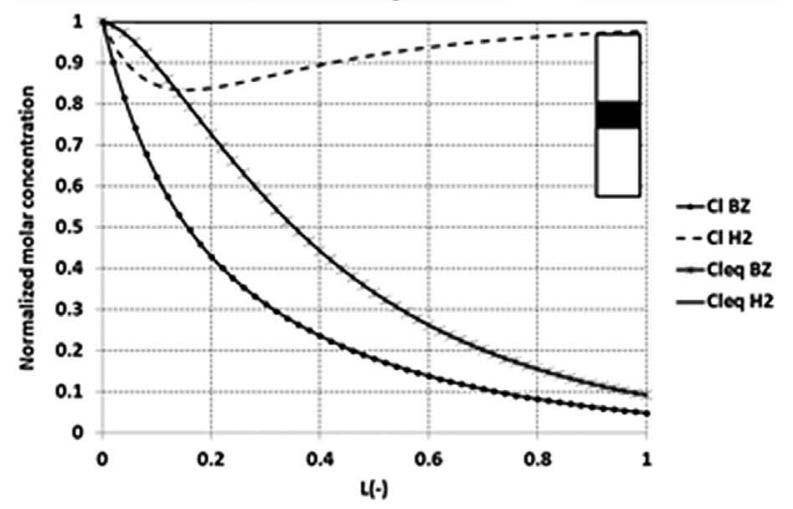

b) Catalyst $B$

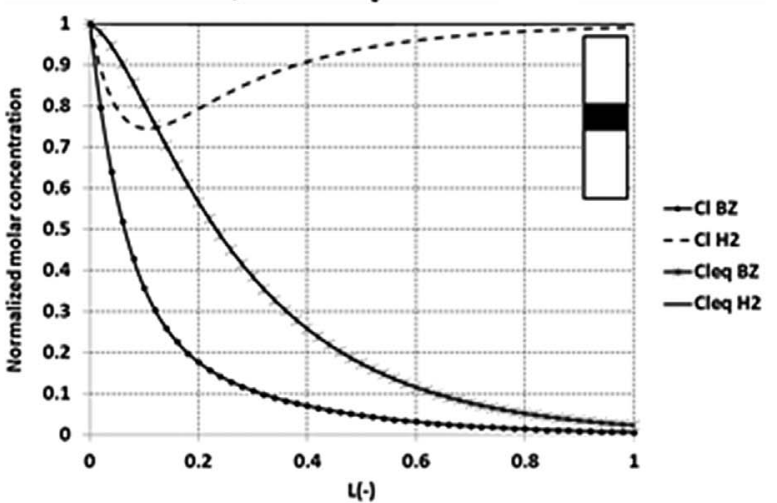

c) Residual benzene molar concentration

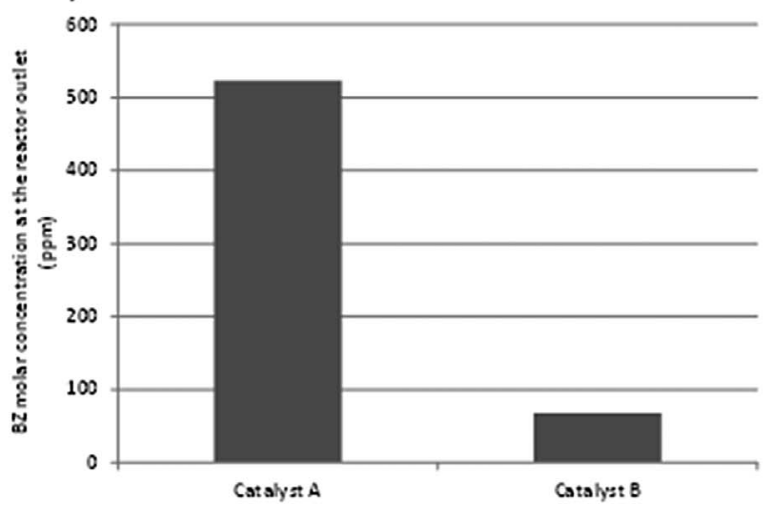

Fig. 10. Liquid interface and liquid normalized concentrations profile for hydrogen and benzene as a function of the normalized reactor axial coordinate for undiluted catalyst and residual benzene at the reactor outlet for both catalysts at $140{ }^{\circ} \mathrm{C}$.

1:4 allows to obtain a benzene outlet concentration of $11 \mathrm{ppm} \mathrm{mol} / \mathrm{mol}$, performances close to the base case, for which the benzene outlet concentration is $10 \mathrm{ppm} \mathrm{mol} / \mathrm{mol}$. The simulation of both catalytic beds uniform dilution with increasing dilution with and without the intermediate inert layer gives similar results (Fig. 11e). The intermediate inert bed allows the performance to be improved, but not significantly, as most of the gas-liquid mass transfer limitations are suppressed through the practice of uniform dilution. The aim of the last set of simulations is to provide information about where to preferably use uniform dilution, and in which proportion. For fast chemical reactions and at rather high conversion $(>70 \%)$, the inert material should be introduced in the first catalytic bed, preferably with a dilution factor of 1:4, as suggested by Figures $11 \mathrm{c}$ and $11 \mathrm{e}$. Indeed, the chemical reaction rate is the highest at the beginning of the reactor, and as a result, one should dilute this part of the reactor rather than downstream catalytic beds. The addition of one inert bed is optional, as the effect on gas-liquid mass transfer limitations is reduced when uniform dilution is considered. The effect of the second catalytic bed dilution on performances is low as the chemical reaction is almost completed at this point (Figs. 11d and 11e).

The simulations carried out for this case study show that catalyst screening of substantially different catalytic formulations can be performed, even with considerable gas-liquid mass transfer limitations. In the case of a specification-driven or close catalytic formulations screening, uniform dilution with a factor of 1:4 is advised. The use of two catalytic beds with different dilution factors split by an intermediate inert bed is also possible. In that case, the first catalytic bed should be diluted by a factor of 1:4 whereas a dilution factor of 1:2 should be sufficient for the second bed. The height of the inert bed can be easily determined by ensuring that the dissolution characteristic time is lower than the residence time within this bed.

\subsection{Optimizing the dilution factor}

The results from both case studies, despite they are intrinsically different, allow to conclude that a dilution factor of $1: 4$ in the uniform dilution configuration is sufficient to minimize the impact of gas-liquid mass transfer limitations on catalytic performance measurements. A sensitivity analysis is performed to understand the evolution of the optimized dilution factor as a function of kinetics at different conversion levels. The result of the HDM conversion evolution with dilution factor for different kinetics and conversion levels is illustrated in Figure 12. It includes the conversion target for neglecting gas-liquid mass transfer limitations, defined as the conversion corresponding to a temperature 


\section{a) Layered dilution}

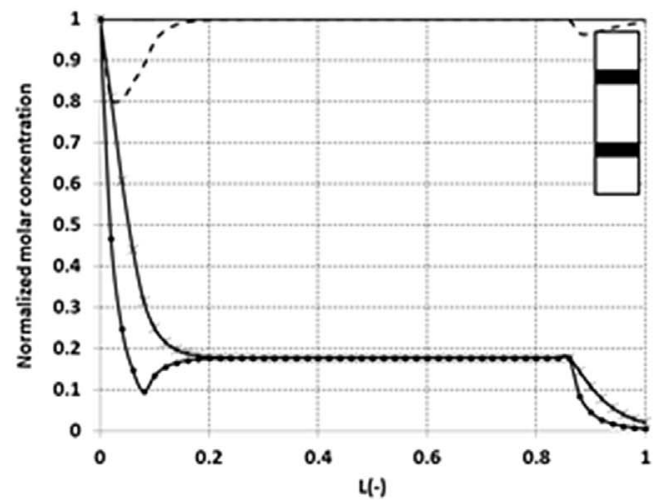

c) Combination $\tau_{\mathrm{L} 1}=1: 4, \tau_{\mathrm{L} 2}=1$

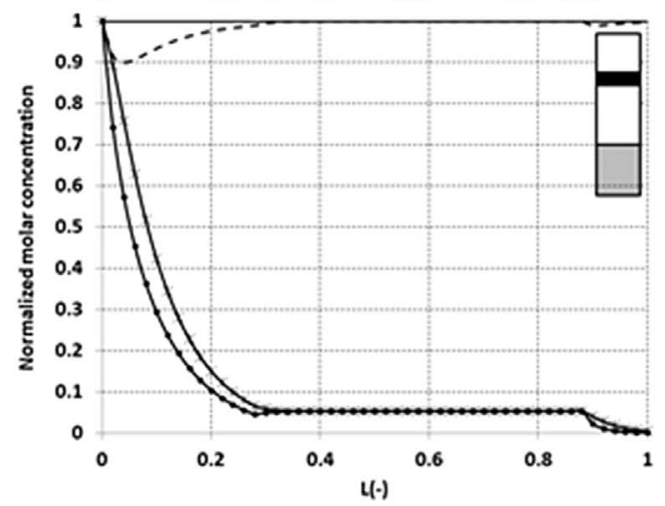

b) Uniform $\tau_{\mathrm{C}}=\tau_{\mathrm{L}}=1: 4$
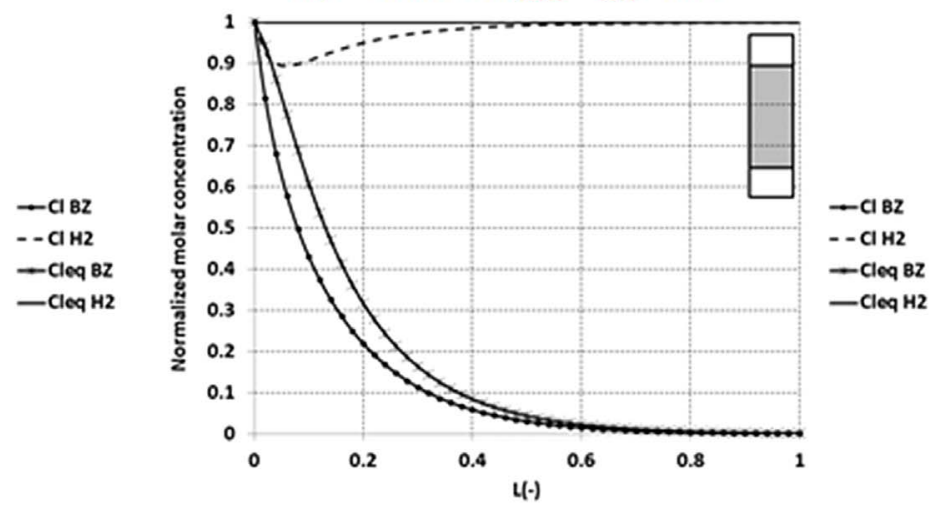

d) Combination $\tau_{\mathrm{L} 1}=1, \tau_{\mathrm{L} 2}=1: 4$

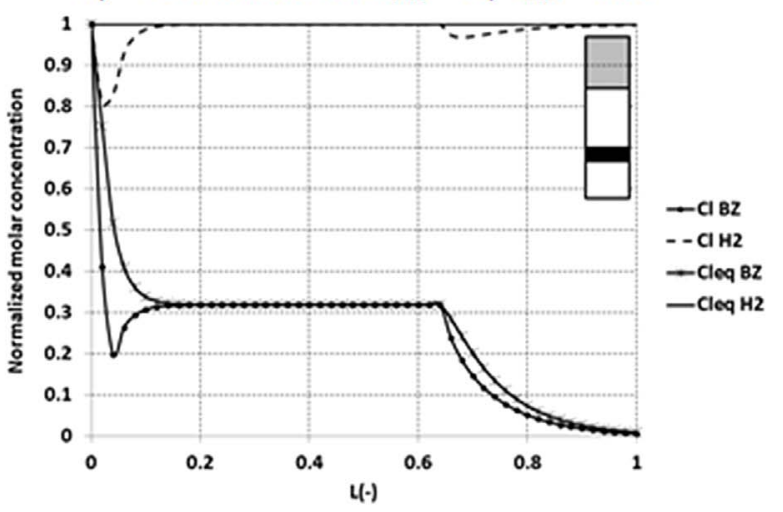

e) Residual benzene molar concentration

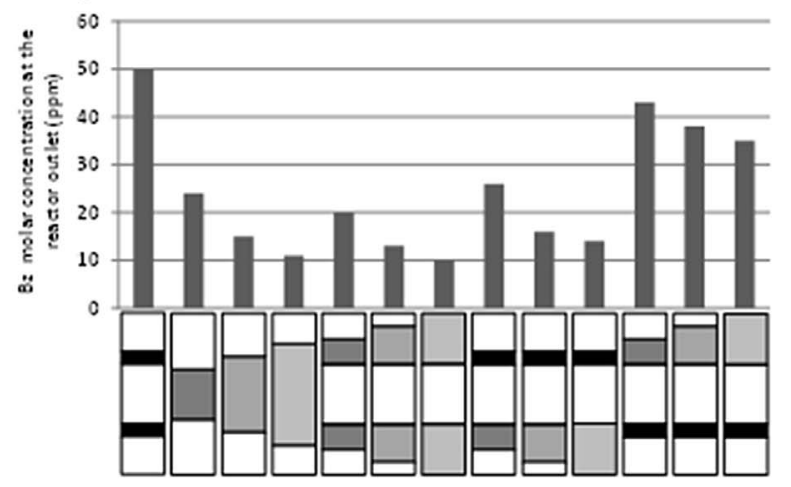

Fig. 11. Liquid interface and liquid normalized concentrations profile for hydrogen and benzene as a function of the normalized reactor axial coordinate for different dilution techniques and residual benzene at the reactor outlet for catalyst B at $140{ }^{\circ} \mathrm{C}$.

$2{ }^{\circ} \mathrm{C}$ lower than the temperature set during numerical experiments $\left(370^{\circ} \mathrm{C}\right)$. This value corresponds to the typical uncertainty of catalytic activity measurements.

The conversion rapidly increases as the dilution factor increases (traduced by a decrease of parameter $\tau$ ) until reaching the conversion at which gas-liquid mass transfer limitations are negligible for all cases. This increase is sharper for faster kinetics due to stronger mass transfer limitations. The minimum dilution factor increases for faster kinetics, as the gas-liquid mass transfer limitations become stronger in that case. The optimized dilution factor decreases with an increase of conversion, which is due to a dramatic drop of the chemical reaction rate near the reactor outlet. This effect is stronger than the gas-liquid mass transfer limitation near the reactor inlet at high conversion, fact that explains why an optimum dilution factor of 1:4 is found for both case studies, although the benzene hydrogenation is quite faster than the oil residue HDM.

The minimum necessary dilution factor can be determined from the following expression, that accounts for external mass transfer effects, kinetics and conversion. The deduction of this equation is exposed in Appendix.

$$
\tau_{\mathrm{L}}=\frac{k_{\mathrm{L}} a}{k_{\mathrm{LS}} a_{\mathrm{LS}}\left(\frac{\alpha}{1-\alpha}\right)\left(1-\frac{k_{\mathrm{LS}} a_{\mathrm{LS}}}{k_{\mathrm{LS}} a_{\mathrm{LS}}+k v_{\mathrm{H}_{2}} C_{520^{\circ} \mathrm{C}^{+}} \varepsilon_{\mathrm{s}} \rho_{\mathrm{s}}}\right)} .
$$




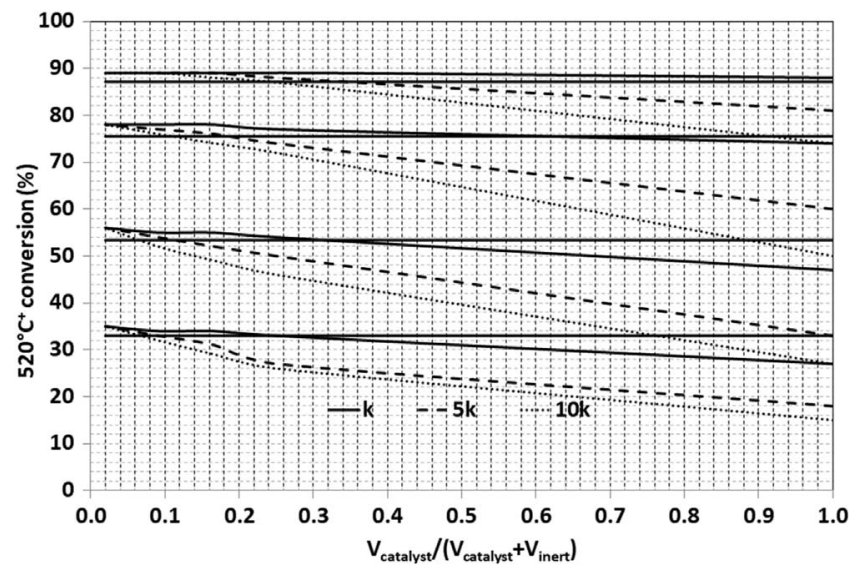

Fig. 12. HDM conversion evolution with dilution factor for different HDM kinetics and conversion levels. The figure includes the conversion target defined as the conversion at which gasliquid mass transfer limitations can be neglected: $33,53.4,75.5$ and $87.1 \%$.

Intuitively, in the case of fast kinetics, the dilution factor to ensure negligible gas-liquid mass transfer limitations should depend on the liquid-solid mass transfer coefficient. The higher the liquid-solid mass transfer coefficient, the higher the dilution needed, as suggested by the criterion. For extremely low kinetics rates, the dilution factor parameter $\tau_{L}$ approaches infinity, which means that no dilution is needed, result expected as, in this case, the operation is expected to be completely controlled by the chemical reaction. Finally, the higher the parameter alpha, the higher the dilution needed, which is intuitive, as a lower gradient between the gas and the liquid phases concentrations requires higher dilution factors.

$\alpha$ depends on the activation energy as well as on the $\Delta T$ uncertainty, which is equal to $2{ }^{\circ} \mathrm{C}$. It can be obtained through the following expression, whose deduction is shown in the Appendix, and in that case, it takes the value of 0.93:

$$
\alpha=\exp \left(\frac{-E_{a}}{R}\left[\frac{1}{T-\Delta T}-\frac{1}{T}\right]\right) \text {. }
$$

In equation (16) $C_{520}^{\mathrm{L}}{ }^{\circ} \mathrm{C}+$ is the $520{ }^{\circ} \mathrm{C}^{+}$cut concentration within the liquid phase at the reactor outlet and it can be obtained by performing a mass balance equation to this lump in the liquid phase by assuming a constant value of 0.93 for $\alpha$. The ratio $\frac{k_{L S} a_{L S}}{k_{L S} a_{L S}+k}$ can be experimentally obtained through the second-order kinetic constant determination. The comparison between the criterion and the graphical results is illustrated in Figure 13. The criterion is validated as a quite good agreement exists between model and criterion data.

\section{Discussion}

This article clearly shows the interest of uniform catalytic bed dilution for minimizing the role of gas-liquid mass transfer on catalytic performance measurements. The obtained results are subject to the model assumptions and

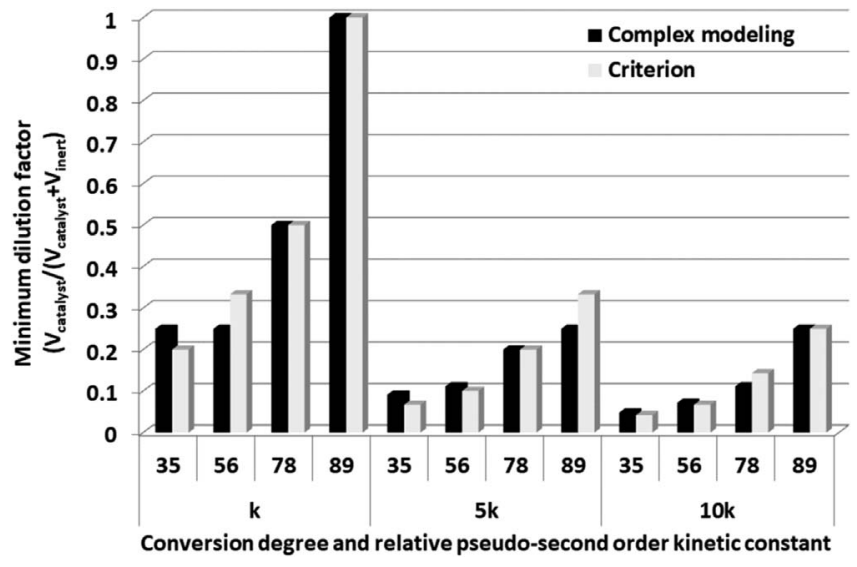

Fig. 13. Validation of the criteria for the determination of the minimum dilution factor as a function of kinetics, conversion and external mass transfer. The minimum dilution factor for the complex modeling corresponds to the dilution factor necessary to achieve $33,53.4,75.5$ and $87.1 \%$ conversion, directly extracted from Figure 12.

simplifications, as no experimental validation is provided. Nevertheless, the simulations are carried out after kinetics calibration with experimental data, which gives robustness to the conclusions. Layered dilution does not offer significant enhancement, thus allowing reactor loading procedures to be simplified for the development of more efficient catalyst testing experimental protocols in some cases. In practice, complex reactor loading may take long time for ensuring experiments reproducibility, mainly when considering high throughput experimentation, in which up to 64 reactors may be used. In that particular case, a 10 min gain of time during each reactor loading (catalyst and inert weighing, loading, etc.) may lead to 5 more days of operator work per year.

The criterion proposed in this work allows the computation of the minimum necessary dilution factor to guarantee a gas-liquid mass transfer limitations free operation. It may achieve important values for high reaction rates at moderate conversions, chemical systems for which liquid-solid mass transfer effects cannot be neglected and thus considered for kinetics determination purposes. The use of other reactor technologies such as stirred reactors is more suitable in that case as liquid-solid mass transfer correlations in upflow gas-liquid fixed-bed lab reactors may introduce some uncertainties during scale-up. The use of other reactor technologies is sometimes discouraged as the kinetics may not be representative from a continuous fixed-bed operation. Special care must be taken when high dilution factors are needed $(>1: 5)$, as the risk of catalyst segregation increases [16-18]. Anyway, it is not worth to use dilution factors higher than 1:10 as, even without catalyst segregation issues, the improvement may be masked by experimental uncertainties for systems in which the liquidsolid mass transfer resistance is lower than 50\%. For systems with liquid-solid mass transfer resistances higher than $50 \%$, the use of the fixed-bed technology for kinetics studies is highly discouraged. Catalyst segregation may induce catalyst by-passing by the reactive mixture, 
leading to an important deviation between observed and intrinsic kinetics when radial dispersion is not sufficient to guarantee perfect mixing conditions in the radial direction. This deviation may be negative for positive reaction orders and positive for negative reaction orders in gas-solid systems, as suggested by Berger et al. [16]. Radial dispersion issues are likely to occur in systems presenting low liquid velocities, such as for example the HDM reaction, or in reactors filled with small powder [30]. In these cases, hydrogen may flow through preferential paths inside the reactor, and dispersion may not be sufficiently high to guarantee a zero-radial-gradient operation. The model considers perfect mixing of the liquid phase in the radial direction, and as a result, radial dispersion is expected to be lumped within the regressed kinetic constant. Since the velocity, reactor diameter and particle size remain unchanged between simulations of each dilution technique, the preferential paths are expected to be the same in practice, and as a result, the conclusions drawn from the study are expected to be valid. One possible way of taking into account radial dispersion in the model is to consider the reactor as a 2D (twodimensional) domain, and to stochastically determined if a given point in the space is either filled with gas or liquid or with catalyst or inert. Experimental porosity, phases holdup, complete wetting conditions and bed dilution should be accounting for as constraints during domain generation, in which mass balances equations coupled with a liquidcell-liquid-cell radial dispersion coefficient are applied and solved for determining the optimized dilution factor to minimize gas-liquid mass transfer and radial dispersion effects.

\section{Conclusion}

Hydrodynamics and external mass transfer modeling in presence of catalyst dilution has been used to evaluate and optimize lab reactor loading. Catalyst dilution represents a versatile and robust solution for gas-liquid mass transfer intensification of gas-liquid fixed-bed lab reactors and for ensuring a reliable experimental data scale-up.

Layered dilution, consisting on separating two consecutive catalytic beds by an inert material bed of the same size as the catalyst, ensures the return to equilibrium conditions in the liquid phase. This technique is poorly effective since limiting species are severely depleted in the liquid phase immediately after entering a new catalytic bed. The addition of multiple beds does not improve gas-liquid mass transfer neither, and the same behavior is observed at the beginning of each catalytic bed.

Uniform dilution, consisting on mixing both the catalyst and the inert material with the same size as the catalyst in a given proportion, substantially decreases gas-liquid mass transfer effects as the local species consumption is decreased whereas mass transfer is kept constant. Increasing dilution factor from 1:2 up to 1:4 rapidly decreases gas-liquid mass transfer limitations. Further improvement through the increase in catalyst dilution may be masked by experimental uncertainties.

Combinations of both types of dilution approaches can be used for high conversion experiments $(>70 \%)$ and with chemical systems presenting either high reactions rates or high stoichiometric factors in presence of mass transfer limitations. Uniform dilution with a dilution factor of 1:4 should be used in the first catalytic bed constituted by $50 \%$ of the catalyst total volume, while a dilution factor of $1: 2$ is expected to be enough for the second catalytic bed. Both beds are separated by an inert bed in order to avoid beds mixture. The dilution of all the catalyst volume by a factor of 1:4 is also expected to give good results from mass transfer limitations reduction considerations.

Screening of quite different catalytic formulations can be carried out without dilution even if the differences in performance are expected to be lower than the intrinsic ones. Whereas dilution must be used during the screening of similar catalytic formulations or when a given specification is required for candidate selection. In the same way, dilution must be used in kinetic studies for scale-up purposes following the guidelines mentioned previously.

A new criterion is proposed in this work to determine the minimum necessary dilution factor to neglect gas-liquid mass transfer limitations as a function of kinetics and external mass transfer and for different levels of conversion. The minimum value of the dilution factor increases with an increase of the chemical reaction rate as gas-liquid mass transfer limitations become stronger in that case, whereas it decreases at higher conversions due to a dramatic drop of the kinetics rate near the reactor exit.

The effect of diluting catalyst with small powder through porosity filling is not considered in this work since no mass transfer correlations are available for this particular case. Small particles are expected to locally change flow pattern and related mass transfer, and they may constitute a good solution for applications limited by liquid-solid mass transfer and/or thermal effects. Nevertheless, the introduction of small powder should be avoided in systems presenting quite low liquid velocities, as the presence of gas preferential paths is very likely in this type of configuration [30].

Acknowledgments. I thank Dr. Matthieu Rolland, IFP Energies nouvelles, for useful discussions and paper revision.

\section{References}

1 Grand View Research (2019) Refinery Catalysts Market Size, Share \& Trends Analysis Report By Material (Zeolites, Chemical Compounds), By Application (FCC, Hydrocracking, Catalytic Hydrotreating), By Region, And Segment Forecasts, 2019-2025, $172 \mathrm{p}$.

2 IEA (2018) The Future of Petrochemicals, International Energy Agency.

3 Hakeem A. (2019) High Throughput catalyst testing to enhance refinery operations, in: SPE Kuwait Oil \& Gas Show and Conference, Society of Petroleum Engineers, 8 p.

4 Wehinger G.D., Kreitz B., Nagy A.J., Turek T. (2020) Characterization of a modular Temkin reactor with experiments and computational fluid dynamics simulations, Chem. Eng. J. 389, 124342. doi: 10.1016/j.cej.2020.124342

5 Figueiredo J.L. (1982) Progress in catalyst deactivation, Springer, Dordrecht. 
6 Mederos F.S., Ancheyta J., Chen J. (2009) Review on criteria to ensure ideal behaviors in trickle-bed reactors, Appl. Catal. A Gen. 355, 1-19.

7 Sie S.T. (1996) Miniaturization of hydroprocessing catalyst testing systems: Theory and practice, AIChE J. 42, 12, 3498-3507.

8 Mears D.E. (1971) The role of axial dispersion in trickle-flow laboratory reactors, Chem. Eng. Sc. 26, 1361-1366.

9 Gierman H. (1988) Design of laboratory hydrotreating reactors: Scaling down of trickle-flow reactors, Appl. Catal. 43, 277-286.

10 Thiele E.W. (1939) Relation between catalytic activity and size of particle, Ind. Eng. Chem. Res. 31, 916-920.

11 Mears D.E. (1971) Tests for transport limitations in experimental catalytic reactors, Ind. Eng. Chem. Process. Des. Dev. 10, 4, 541-547.

12 Rolland M., Fonte C. (2015) Incertitude induced by testing a small number of catalytic pellets in fixed beds, Chem. Eng. Sci. 138, 698-705.

13 Raynal L., Augier F., Bazer-Bachi F., Haroun Y., Pereira da Fonte C. (2016) CFD applied to process development in the oil and gas industry - a review, Oil Gas Sci. Technol. - Rev. IFP Energies nouvelles 71, 42.

14 Dixon A.G., Nijemeisland M. (2001) CFD as a design tool for fixed-bed reactors, Ind. Eng. Chem. Res 40, 23, 5246-5254.

15 Dorai F., Teixeira C.M., Rolland M., Climent E., Marcoux M., Wachs A. (2015) Fully resolved simulations of the flow through a packed bed of cylinders: Effect of size distribution, Chem. Eng. Sci. 129, 180-192.

16 Berger R.J., Perez-Ramirez J., Kapteijn F., Moulijn J.A. (2002) Catalyst performance testing. Radial and axial dispersion related to dilution in fixed-bed laboratory reactors, Appl. Catal. A Gen. 227, 321-333.

17 Berger R.J., Perez-Ramirez J., Kapteijn F., Moulijn J.A. (2002) Catalyst performance testing: the influence of catalyst bed dilution on the conversion observed, Chem. Eng. J. 90, 173-183.

18 Berger R.J., Perez-Ramirez J., Kapteijn F., Moulijn J.A. (2002) Catalyst performance testing: bed dilution revisited, Chem. Eng. Sci. 57, 4921-4932.

19 Taniewski M., Lachowicz A., Skutil K., Czechowicz D. (1996) The effect of dilution of the catalyst bed on its heattransfer characteristics in oxidative coupling of methane, Chem. Eng. Sci. 51, 18, 4271-4278.

20 Rolland M. (2014) Des limites à la reduction d'échelle en réacteur de test catalytique en lit fixe ? PhD thesis, Université Claude Bernard - Lyon I, Lyon, 214 p.

21 Khadilkar M.R., Wu Y.X., Al-Dahhan M.H., Duduković M.P., Colakyan M. (1996) Comparison of trickle-bed and upflow reactor performance at high pressure: Model predictions and experimental observations, Chem. Eng. Sci. 51, 10, 2139-2148.

22 Goto S., Levec J., Smith J.M. (1975) Mass transfer in packed beds with two-phase flow, Ind. Eng. Chem. Process. Des. Dev. 14, 4, 473-478.

23 Saada N.Y. (1972) Assessment of interfacial area in co-current two-phase flow in packed beds, Chim. Ind. Génie chimique 105, 1415.

24 Larachi F., Belfares L., Iliuta I., Grandjean B.P.A. (2003) Heat and mass transfer in cocurrent gas-liquid packed beds. Analysis, recommendations and new correlations, Ind. Eng. Chem. Res. 42, 222-242.

25 Belfares L., Cassanello M.C., Grandjean B.P.A., Larachi F. (2001) Liquid back-mixing in packed-bubble column reactors: a state-of-the-art correlation, Catal. Today 64, 321-332.
26 Bensetiti Z., Larachi F., Grandjean B.P.A. (1997) Liquid saturation in cocurrent upflow fixed-bed reactors: a state-ofthe-art correlation, Chem. Eng. Sci. 52, 4239-4247.

27 Poling B.E., Prausnitz J.M., O'Connell J.P. (2000) The properties of Gases and Liquids, 5th edn., McGraw-Hill Professional.

28 Toppinen S., Salmi T., Rantakylae T.K., Aittamaa J. (1996) Kinetics of the Liquid-Phase Hydrogenation of Benzene and Some Monosubstituted Alkylbenzenes over a Nickel Catalyst, Ind. Eng. Chem. Res. 35, 1824-1833.

29 Ranz W.E., Marshall W.R. (1952) Evaporation from Drops, Chem. Eng. Prog. 48, 141-146, 173-180.

30 Moulijn J.A., Makkee M., Berger R.J. (2016) Catalyst testing in multiphase micro-packed-bed reactors; criterion for radial mass transport, Catal. Today 259, 354-359.

\section{Appendix}

\section{A.1 Criterion deduction}

For a given reactor slice, the gas-liquid flux of the limiting species must be equal to the liquid-solid and to the chemical flux, as suggested by the following equation:

$$
\begin{aligned}
k_{\mathrm{L}} a\left(\frac{C_{\mathrm{H}_{2}}^{\mathrm{G}}}{H}-\alpha \frac{C_{\mathrm{H}_{2}}^{\mathrm{G}}}{H}\right) & =\tau_{\mathrm{L}} k_{\mathrm{LS}} a_{\mathrm{LS}}\left(\alpha \frac{C_{\mathrm{H}_{2}}^{\mathrm{G}}}{H}-C_{\mathrm{H}_{2}}^{\mathrm{F}}\right) \\
& =\tau_{\mathrm{L}} \varepsilon_{\mathrm{s}} \rho_{\mathrm{s}} v_{\mathrm{H}_{2}} k C_{\mathrm{H}_{2}}^{\mathrm{F}} C_{520^{\circ} \mathrm{C}^{+}}^{\mathrm{F}} .
\end{aligned}
$$

The concentration in the film surrounding the catalyst can be determined through the equality between the liquidsolid and the chemical flux, leading to the following expression:

$$
C_{\mathrm{H}_{2}}^{\mathrm{F}}=\frac{k_{\mathrm{LS}} a_{\mathrm{LS}} \frac{C_{\mathrm{H}_{2}}^{\mathrm{G}}}{H} \alpha}{k_{\mathrm{LS}} a_{\mathrm{LS}}+\varepsilon_{\mathrm{s}} \rho_{\mathrm{s}} k v_{\mathrm{H}_{2}} C_{520^{\circ} \mathrm{C}^{+}}^{\mathrm{F}}} .
$$

Introducing equation (A.2) in the first equality of equation (A.1) and neglecting external mass transfer limitations for the liquid phase reactant yields the criterion developed in this work for the determination of the minimum necessary dilution factor allowing gas-liquid mass transfer limitations to be neglected:

$$
\tau_{\mathrm{L}}=\frac{k_{\mathrm{L}} a}{k_{\mathrm{LS}} a_{\mathrm{LS}}\left(\frac{\alpha}{1-\alpha}\right)\left(1-\frac{k_{\mathrm{LS}} a_{\mathrm{LS}}}{k_{\mathrm{LS}} a_{\mathrm{LS}}+\varepsilon_{\mathrm{s}} \rho_{\mathrm{s}} k_{\mathrm{H}_{2}} 2_{520^{\circ} \mathrm{C}^{+}}^{\mathrm{L}}}\right)}
$$

" $\alpha$ " can be calculated by performing a mass balance to the $520{ }^{\circ} \mathrm{C}^{+}$cut in the liquid phase, as shown in equation (A.4):

$$
\ln (1-X)=-\frac{k(T)}{L H S V} \alpha \frac{C_{\mathrm{H}_{2}}^{\mathrm{G}}}{H} \varepsilon_{\mathrm{s}} \rho_{\mathrm{s}}=-\frac{k(T-\Delta T)}{L H S V} \frac{C_{\mathrm{H}_{2}}^{\mathrm{G}}}{H} \varepsilon_{\mathrm{s}} \rho_{\mathrm{s}} .
$$

The second equality of the previous equation allows the computation of $\alpha$.

$$
\alpha=\frac{k(T-\Delta T)}{k(T)}=\exp \left(-\frac{E_{\mathrm{a}}}{R}\left[\frac{1}{T-\Delta T}-\frac{1}{T}\right]\right) .
$$

